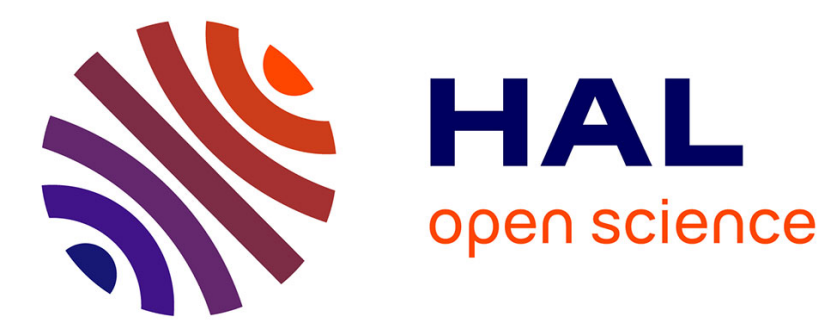

\title{
Synthesis of GdBO3:Eu3+ nanophosphors via acetylacetone assisted aqueous sol-gel route: Effect of some synthesis parameters
}

\author{
M. Seraiche, L. Guerbous, Rachid Mahiou, A. Potdevin
}

\section{- To cite this version:}

M. Seraiche, L. Guerbous, Rachid Mahiou, A. Potdevin. Synthesis of GdBO3:Eu3+ nanophosphors via acetylacetone assisted aqueous sol-gel route: Effect of some synthesis parameters. Optical Materials, 2020, 109, pp.110339. 10.1016/j.optmat.2020.110339 . hal-02991785

\section{HAL Id: hal-02991785 \\ https://hal.science/hal-02991785}

Submitted on 10 Dec 2020

HAL is a multi-disciplinary open access archive for the deposit and dissemination of scientific research documents, whether they are published or not. The documents may come from teaching and research institutions in France or abroad, or from public or private research centers.
L'archive ouverte pluridisciplinaire HAL, est destinée au dépôt et à la diffusion de documents scientifiques de niveau recherche, publiés ou non, émanant des établissements d'enseignement et de recherche français ou étrangers, des laboratoires publics ou privés. 


\title{
Synthesis of $\mathrm{GdBO}_{3}: \mathrm{Eu}^{3+}$ nanophosphors via acetylacetone assisted aqueous sol-gel route: Effect of some synthesis parameters
}

The corrections made in this section will be reviewed and approved by a journal production editor.

M. Seraiche ${ }^{a, *}$ seraiche28@hotmail.fr, L. Guerbous ${ }^{b, * *}$ guerbous@yahoo.fr, R. Mahiou ${ }^{c}$, A. Potdevin ${ }^{c}$

${ }^{a}$ Faculty of Sciences, M ${ }^{\text {ed }}$ Boudiaf University -M'sila- BP 166 M'sila, 28000, Algeria

baser Physic Department, Physic Division, Algiers Nuclear Research Center(CRNA), 02, Bd Frantz Fanon, BP 399, Algiers, 16000, Algeria

'Université Clermont Auvergne, CNRS, SIGMA Clermont, Institut de Chimie de Clermont-Ferrand, F63000, Clermont-Ferrand, France

*Corresponding author.

** Corresponding author.

\begin{abstract}
Nano-sized $\mathrm{Eu}^{3+}$-doped $\mathrm{GdBO}_{3}$ vaterite type nanophosphors have been synthesized successfully via acetylacetone assisted aqueous sol-gel route. Systematic investigation of the influence of $\mathrm{Eu}^{3+}$ ion content and $\mathrm{pH}$ value of the suspension of precursors on structural, morphological and luminescence spectroscopic properties has been performed. X-ray powder diffraction (XRD), Fourier transform infrared spectroscopy (FTIR), Raman spectroscopy, field emission-scanning electron microscopy (FE-SEM), Thermogravimetric and differential thermal gravimetry (TG/DTA), room temperature steady and time resolved photoluminescence (PL) spectroscopy techniques were employed to characterize the obtained powder samples. It has been found that the $\mathrm{Eu}^{3+}$ ion content and $\mathrm{pH}$ value precursors suspension have important effect on the structural, morphology and emission properties. The XRD analysis reveals that $\mathrm{GdBO}_{3}: 10 \% \mathrm{~mol} \mathrm{Eu}^{3+}$ synthesized at $\mathrm{pH}=2$ and $\mathrm{pH}=10$ exhibit the quasi-purest $\mathrm{Pb}_{3} / \mathrm{mmc}$ vaterite structure. The vibrational absorption of $\left(\mathrm{BO}_{3}\right)^{3-}$ group is assigned to the $\mathrm{GdBO}_{3}$ with calcite type or other vaterite structure namely triclinic and monoclinic. The morphologies of $\mathrm{GdBO}_{3}$ particles size increases with increasing of $\mathrm{pH}$ value. All sample present only the orange-red colors emission from ${ }^{5} \mathrm{D}_{0}$ levels to the ${ }^{7} \mathrm{~F}_{\mathrm{J}}$ levels $(\mathrm{J}=0-3)$ of $\mathrm{Eu}^{3+}$ ion. Furthermore, it was found that $10 \%$ concentration of $\mathrm{Eu}^{3+}$ presents the quenching of emission in $\mathrm{GdBO}_{3}$. Also, it was that the emission intensity was affected by the $\mathrm{pH}$ value and sample with $\mathrm{pH}=10$ exhibits the highest emission intensity. The asymmetry ratio parameter $\mathrm{R}$ between red
\end{abstract}


and orange emission intensities in function of $\mathrm{Eu}^{3+}$ content and $\mathrm{pH}$ value is determinate and discussed.

Keywords: $\mathrm{GdBO}_{3}: \mathrm{Eu}^{3+}$; Phosphors; Aqueous sol-gel; Photoluminescence

\section{Introduction}

Synthesis of rare earth ions doped inorganic nanophosphors with controllable, very clear morphologies has been an important challenge of modern materials physics and chemistry. Actually, it is well established that the properties of such luminescent nano-crystals depend on their structure, phase, dimensionality, shape, and size distribution in addition to their chemical composition. Actually, the industry demand is still very important in this field of advanced innovative materials due to their potential applications in many luminescent devises such as scintillators [1-3], Plasma Display Panels (PDP) [4-13]and Hg-free fluorescent lamp [14], $\underline{\text { Light-emitting diode }}$ LEDs [15].Among these materials, $\mathrm{REBO}_{3}$ Orthoborates have attracted much more attention. Thanks to their special optical properties, low synthesis temperature, low toxicity, high stability, large band gap, strong vacuum ultraviolet (VUV) absorption and high ultraviolet and optical damage threshold [16-19]. Up until now, there is no consensus about the crystallographic structure of vaterite and several structural with different space groups have been published such as: a disordered $\left(\mathrm{P}_{3} / \mathrm{mmc}\right)$ and an ordered hexagonal $\left(\mathrm{P}_{3} / \mathrm{mcm}\right)$ structure [20], $P 6^{-} \mathrm{c} 2$ space group [21], monoclinic $\left(\mathrm{C}_{2} / \mathrm{c}\right)$ pseudo-vaterite-type structure [22], pseudo-wollastonite-type structure to Morganet.al. [23], hexagonal $\left(\mathrm{P}_{3} / \mathrm{m}\right)$ [24] and recently $\left(\mathrm{C}_{2} / \mathrm{c}\right)$ monoclinic and $\mathrm{P}_{1}$ triclinic phases [ 25].

Some red orthoborates phosphors such as $\mathrm{YBO}_{3}: \mathrm{Eu}^{3+}$ is actually used widely as commercial phosphors. Because of its poor chromaticity, due to the dominant orange ${ }^{5} \mathrm{D}_{0} \rightarrow{ }^{7} \mathrm{~F}_{1}$ transition compared to red ${ }^{5} \mathrm{D}_{0} \rightarrow{ }^{7} \mathrm{~F}_{2}$ transition, $\mathrm{REBO}_{3}: \mathrm{Eu}^{3+}$ does not make the requested VUV red luminescent material [26]. In fact, the red ${ }^{5} \mathrm{D}_{0} \rightarrow{ }^{7} \mathrm{~F}_{2}$ transition is very sensitive to the symmetry of the crystal field around $\mathrm{Eu}^{3+}$ ions and its emission intensity is high if the symmetry is low. It is already suggested that the problem of the low chromaticity, can be resolved by lowering of symmetry of the crystal field. Therefore, the position of $\mathrm{Eu}^{3+}$ ion in $\mathrm{REBO}_{3}: \mathrm{Eu}^{3+}$ nanocrystals Orthoborates strongly affects their spectroscopic properties. Several methods have been performed to reduce the $\mathrm{Eu}^{3+}$ site symmetry: (i) by developing of such material with different crystal structure, in which $\mathrm{Eu}^{3+}$ ions occupy sites with low-symmetry environment [25], (ii) by synthesizing of nanoscaled $\mathrm{REBO}_{3}: \mathrm{Eu}^{3+}$ phosphors. In fact, by decreasing of the crystallite size, the number of $\mathrm{Eu}^{3+}$ ions occupying the surface with distortion of inversion symmetry can be increased. Therefore, using nanocrystals phosphors could be improved chromaticity [27-29]. Furthermore, it is well known that the method of synthesis has an important influence on the properties of prepared nanomaterials [30]. Indeed, $\mathrm{GdBO}_{3}: \mathrm{Eu}^{3+}$ micro/nanophosphors have been synthesized by several various methods, such as solid-state reaction, hydrolysis, ultrasonic spray cost alternative approach to synthesizing novel nanoscale inorganic materials activated by the rare earth ions in powders and films forms. This method have becomes very popular due to its versatility, better purity, low processing temperature, and the possibility of controlling the size and morphology of particles. In addition, the doped nanomaterials prepared by sol-gel method are characterized by their ability to provide uniform distribution of the dopant within the host phase. Moreover, within the sol-gel method, different conditions of synthesis influencing the final products are very important parameters such as complexing and chelating agents, dopant concentration, $\mathrm{pH}$ value of solution and annealing temperature. The $\mathrm{pH}$ value of the solution plays a crucial role and its change can cause some alteration in structural, the morphological and spectroscopic properties $[31,32]$. 
In this work, $\mathrm{GdBO}_{3}: \mathrm{Eu}^{3+}$ orthoborates vaterite type nanophosphors have been synthesized by a simple aqueous sol-gel method using the acetylacetone $\left(\mathrm{CH}_{3} \mathrm{COCH}_{2} \mathrm{COCH}_{3}\right)$ as chelating agent. A systematic study of the effect of only two synthesis parameters namely the $\mathrm{Eu}^{3+}$ ion content $(0.5,1,2,3,10,15$ and 20 mol \%) and $\mathrm{pH}$ value precursors suspension, extending from acid to basic states $(\mathrm{pH}=2,4,7,8$ and 10) on the structural, morphology and photoluminescence spectroscopic has been performed. In this study, we begin to fix the $\mathrm{pH}$ value $(\mathrm{pH}=2)$ and we optimize the value of $\mathrm{Eu}^{3+}$ content and after that the $\mathrm{pH}$ value is optimized. Thus, structural purity and luminescence properties are the criteria for selecting the best parameter. Furthermore, in this work, we demonstrate that both $\mathrm{Eu}^{3+}$ ion content and the $\mathrm{pH}$ value play a significant role in the determination of the phase purity and the photoluminescence properties of $\mathrm{GdBO}_{3}: \mathrm{Eu}^{3+}$ nanoparticles.

\section{Experimental details}

\subsection{Samples preparation}

$\mathrm{GdBO}_{3}: \mathrm{Eu}^{3+}$ nanopowders were prepared by aqueous sol-gel method. First, in order to determine the quenching concentration of $\mathrm{Eu}^{3+}$ ions in $\mathrm{GdBO}_{3}$ host, the $\mathrm{GdBO}_{3}$ was doped with various concentration of $\mathrm{Eu}^{3+}$ with its general formula $\mathrm{Gd}_{1-\mathrm{x}} \mathrm{Eu}_{\mathrm{x}} \mathrm{BO}_{3}(\mathrm{x}=0.5,1,2,3,10,15$ and 20) at $\mathrm{pH}=2$. For getting this material, stoichiometric amounts of high purity gadolinium oxide $\mathrm{Gd}_{2} \mathrm{O}_{3}$ (99.999\%), europium oxide $\mathrm{Eu}_{2} \mathrm{O}_{3}$ (99.999\%) and boric acid $\mathrm{H}_{3} \mathrm{BO}_{3}$ were dissolved in de-ionized water by the addition of nitric acid $\left(\mathrm{HNO}_{3}\right)$. In order to compensate the volatilization of $\mathrm{B}_{2} \mathrm{O}_{3}$ at high temperature during the heating treatment, an excess of $15 \%$ mol of $\mathrm{H}_{3} \mathrm{BO}_{3}$ was added into the raw materials. The mixed solution was stirred at room temperature for $12 \mathrm{~h}(750 \mathrm{rpm})$. Then, a transparent solution was obtained and an amount of acetylacetone $\left(\mathrm{CH}_{3} \mathrm{COCH}_{2} \mathrm{COCH}_{3}\right)$ corresponding to $1 \mathrm{~mL}$ for $1 \mathrm{~g}$ of product was added as complexing agent (Fig. 1). The chemical reaction can be described with stoichiometric equation following:

$(1-\mathrm{x}) \mathrm{Gd}_{2} \mathrm{O}_{3}+\mathrm{xEu}_{2} \mathrm{O}_{3}+2 \mathrm{H}_{3} \mathrm{BO}_{3}+3 \mathrm{HNO}_{3}+\mathrm{C}_{5} \mathrm{H}_{8} \mathrm{O}_{2} \rightarrow 2\left(\mathrm{Gd}_{1-\mathrm{x}} \mathrm{Eu}_{\mathrm{x}} \mathrm{BO}_{3}\right)+5 \mathrm{CO}_{2} \uparrow+4 \mathrm{H}_{2} \mathrm{O} \uparrow+3 \mathrm{NH}_{3} \uparrow$

alt-text: Fig. 1

Fig. 1 


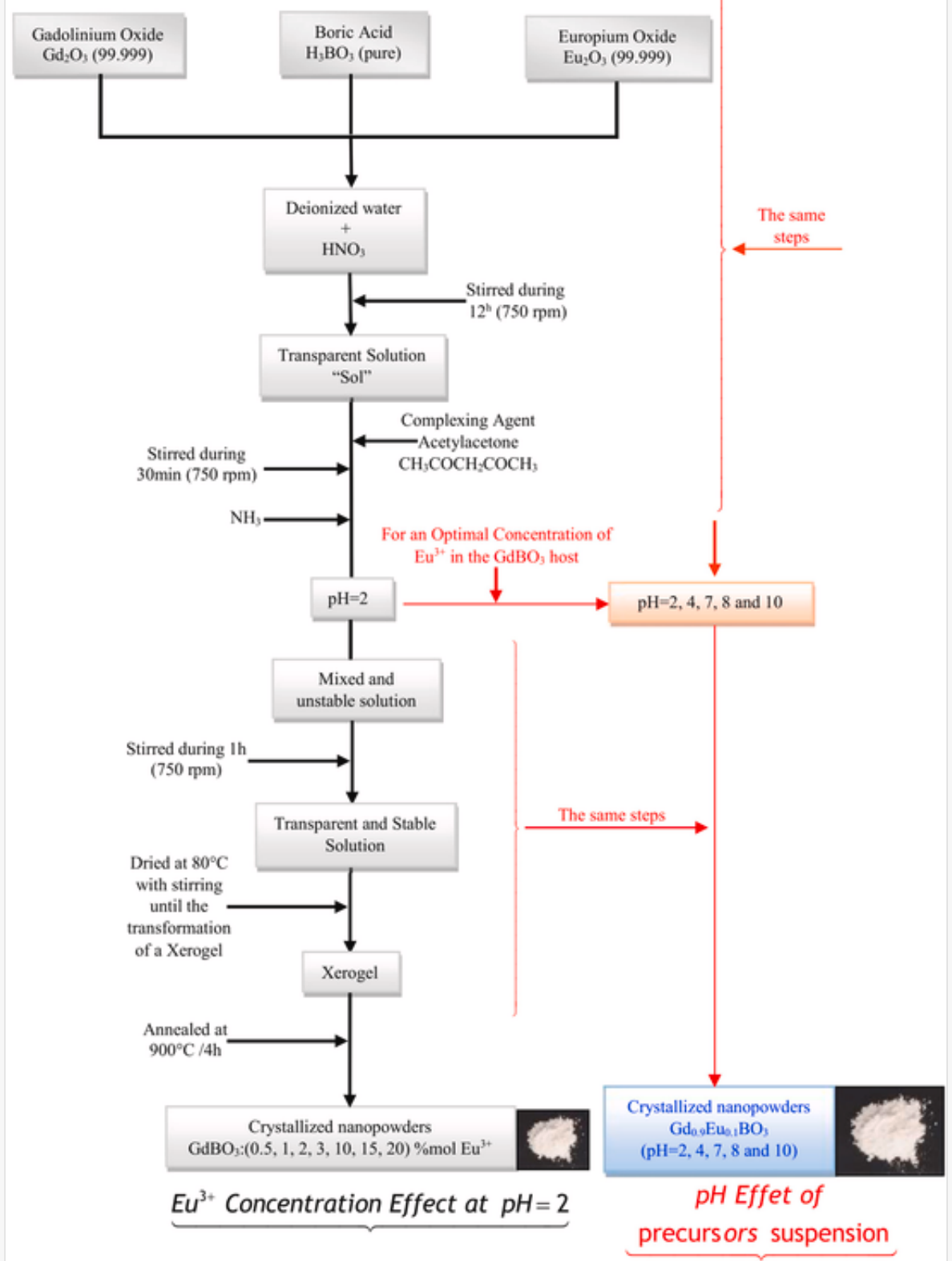

Schematic diagram of the synthesis $\mathrm{Eu}^{3+}$ doped $\mathrm{GdBO}_{3}$ by aqueous sol-gel route.

To stabilize the solution, stirring was carried out for $30 \mathrm{~min}$. After that, the $\mathrm{pH}$ value of precursors suspension was adjusted by adding ammonium hydroxide $\mathrm{NH}_{4} \mathrm{OH}$ at $\mathrm{pH}=2$. This solution was then stirred an extra hour and a homogeneous and transparent aqueous solution was obtained. The resulting solution was dried at $80{ }^{\circ} \mathrm{C}$ 
until transforming in to a Xerogel. Finally, the Xerogel were introduced in a furnace and heated in air at $900{ }^{\circ} \mathrm{C}$ for $4 \mathrm{~h}$ for different $\mathrm{Eu}^{3+}$ concentration. Secondly, the preparation of $\mathrm{GdBO}_{3}$ doped with the $\mathrm{Eu}^{3+}$ obtained optimal concentration at different $\mathrm{pH}$ of precursors suspension namely $\mathrm{pH}=2,4,7,8$ and 10 has been done by the same steps as we saw in the first part of this synthesis (Fig. 1).

\subsection{Characterization}

The phase identification and the related properties of the nanopowders were investigated by X-ray diffraction (XRD) technique a PAN analytical X'Pert (Philips) PRO using $\mathrm{CuK}_{\alpha}$ radiation $(\lambda=1.54059 \AA)$ operated at $45 \mathrm{kV}$ and $40 \mathrm{~mA}$. A symmetric $(\theta-\theta)$ scans were performed from $10^{\circ}$ to $90^{\circ} 2 \theta$ with a step width of $0.02^{\circ}$. All the data were processed by X'Pert High Score plus Software with commercial databases (FWHM deduction and peak identification). Rietveld refinement was done with help of the FullProf software. Thermogravimetric analysis (TG) and differential thermal gravimetry (DTA) were measured by SETARAM SetsysEv 1750 (TGADTA 1600) instrumentation. Micrographs were investigated by means of a ZEISS Supra 55VP Scanning Electron Microscope (SEM) operating in high vacuum at $3 \mathrm{kV}$, using secondary electron detector (EverhartThornley detector). Specimens were prepared by sticking powder onto the surface of an adhesive carbon film. Raman spectra were recorded at room temperature under excitation at $514.5 \mathrm{~nm}$ supplied by a Spectra PhysicsStabilite 2017-100 mW argon laser, using a T64000 Jobin-Yvon spectrometer equipped with a CCD detector cooled with liquid nitrogen. For all the samples, the acquisition time was fixed at $30 \mathrm{~s}$ and three measurement cycles were performed. The infrared spectra were recorded in the range of $400-4000 \mathrm{~cm}^{-1}$ with a Nicolet-IR 380 Fourier transform infrared (FTIR) spectrometer. The steady and time-resolved photoluminescence spectra were carried out using PerkinElmer (LS-50B) luminescence spectrometer with pulsed Xe lamp excitation at room temperature as described in [33].

\section{Experimental results and discussion}

\subsection{Structural analysis}

Fig. 2(a)shows the powder XRD patterns of the synthesized $\mathrm{Gd}_{1-\mathrm{x}} \mathrm{Eu}_{\mathrm{x}} \mathrm{BO}_{3}(\mathrm{x}=0.005,0.01,0.02,0.03,0.1$, 0.15 and 0.2 ) at $\mathrm{pH}=2$ with $15 \%$ excess of $\mathrm{H}_{3} \mathrm{BO}_{3}$, annealed at $900{ }^{\circ} \mathrm{C}$ for 4 h duration. All diffraction peaks in Fig. 2 was indexed according to the hexagonal phase of $\mathrm{GdBO}_{3}$ as listed in JCPDS files (No. 74-1932). In this system, it is found that crystallographic structure purity is highly dependent on the $\mathrm{Eu}^{3+}$ concentration and introducing the $\mathrm{Eu}^{3+}$ dopant drastically changes the host matrix structure. In fact, from the patterns of Fig. 2(a), one can easily observe that it exist three concentration regions, according to the existence of the parasite phases, especially, High temperature phase $\left(\mathrm{HT}-\mathrm{GdBO}_{3}\right)$, indicate by down arrow. The evolution of parasitic phases with $\mathrm{Eu}^{3+}$ content is as follows: a first is the low $\mathrm{Eu}^{3+}$ concentration region, from 0.5 at $\%$ to that of 3 at $\%$, in which the parasite phase peaks are present. The second region around 10 at $\%$, in which the parasite phase peaks vanished completely and $\mathrm{GdBO}_{3}$ give a quasi-purest vaterite phase. From 15 to 20 at \%, constitute the third region, in which the parasitic phases reappear, which become more intense. Although, all samples are prepared in the same conditions, it did not prevent this highly dependence of $\mathrm{GdBO}_{3}$ phase on $\mathrm{Eu}^{3+}$ content. Usually the parasitic phases are not observable for low concentrations of the dopant, but can appear for high concentrations. In the present work is the opposite was observed, indicating that there are other factors involved and their effects is more important than that of the concentration. This phenomenon has been observed in orthoborates $\mathrm{LnBO}_{3}$ prepared by solid state reaction [26]. Some authors have already noticed the dependence of the phases produced as a function of the concentration of the dopant. Szczeszak et al. [34] found that in $\mathrm{La}_{1-\mathrm{x}} \mathrm{Eu}_{\mathrm{x}} \mathrm{BO}_{3}$ and 
$\mathrm{La}_{1-\mathrm{x}} \mathrm{Tb}_{\mathrm{x}} \mathrm{BO}_{3}$ nanopowders synthesized by sol-gel Pechini method the aragonite phase purity depend on the $\mathrm{Eu}^{3+}$ and $\mathrm{Tb}^{3+}$ concentration, which connected just to the annealing temperature.

alt-text: Fig. 2(a)

\section{Fig. 2(a)}

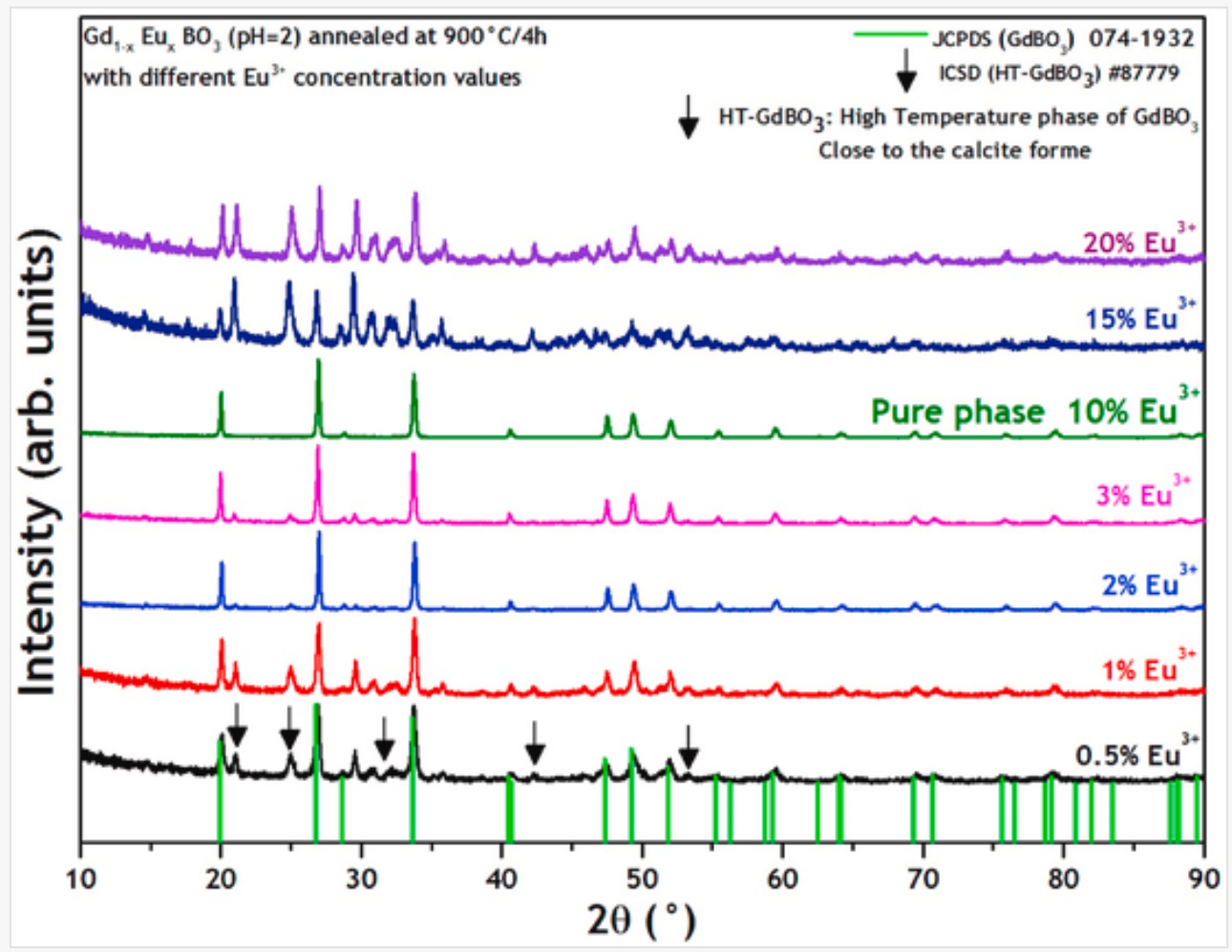

. XRD patterns of $\mathrm{Gd}_{1-\mathrm{x}} \mathrm{Eu}_{\mathrm{X}} \mathrm{BO}_{3}(\mathrm{pH}=2)$ annealed at $900{ }^{\circ} \mathrm{C}$ for $4 \mathrm{~h}$ synthesized by aqueous sol-gel route.

The sample with 10 at $\% \mathrm{Eu}^{3+}$ content presents an apparent pure hexagonal vaterite phase compared to the other concentration and it was chosen for the study of the $\mathrm{pH}$ value effect.

Fig. 2(b) shows the powder XRD patterns of the $\mathrm{GdBO}_{3}: 10$ at $\% \mathrm{Eu}^{3+}$ prepared with $15 \%$ excess of $\mathrm{H}_{3} \mathrm{BO}_{3}$ and prepared at different $\mathrm{pH}$, ranging from $\mathrm{pH}=2$ to 10 , annealed at $900{ }^{\circ} \mathrm{C}$ for $4 \mathrm{~h}$. As it was observed that for both $\mathrm{pH}=2$ and $\mathrm{pH}=10$, the samples exhibit a pure hexagonal $\mathrm{GdBO}_{3}$ vaterite structure. For the other $\mathrm{pH}$ values (4, 7 and 8), parasitic phases are also observed, such as $\mathrm{HT}_{-} \mathrm{GdBO}_{3}$, indicated by down arrow. This demonstrated that the $\mathrm{pH}$ value has an effect on the purity of $\mathrm{GdBO}_{3}$ crystallographic structure. Indeed, the explanation of the mechanisms responsible for the formation of the structural phases produced is very complicated. In fact, the $\mathrm{B}_{2} \mathrm{O}_{3}$ is much more volatile than the gadolinium and europium oxides leading to stoichiometric imbalance [26]. Furthermore, it is not possible to control the amount of $\mathrm{B}_{2} \mathrm{O}_{3}$ which can volatilize during the synthesis in a random manner. This stoichiometric deviation can influences the reaction rate of gadolinium oxide with europium and boron oxides, which can produces additional phase traces such as gadolinium oxides $\left(\mathrm{Gd}_{2} \mathrm{O}_{3}\right)$, borates oxide $\left(\mathrm{Gd}_{3} \mathrm{BO}_{6}\right)$ [26] and/or other possible parasitic unknown phases. Consequently, from the above, we can say that the formation of $\mathrm{GdBO}_{3}: \mathrm{x}$ at $\% \mathrm{Eu}^{3+}$ in it pure vaterite phase and/or others additional phases depends on all oxides concentration present in real time $\left(\mathrm{B}_{2} \mathrm{O}_{3}, \mathrm{Gd}_{2} \mathrm{O}_{3}\right.$ and $\mathrm{Eu}_{2} \mathrm{O}_{3}$ ) during the reaction and depends also to the used synthesis method ( $\mathrm{pH}$ value, annealing temperature, duration, reagent..). 


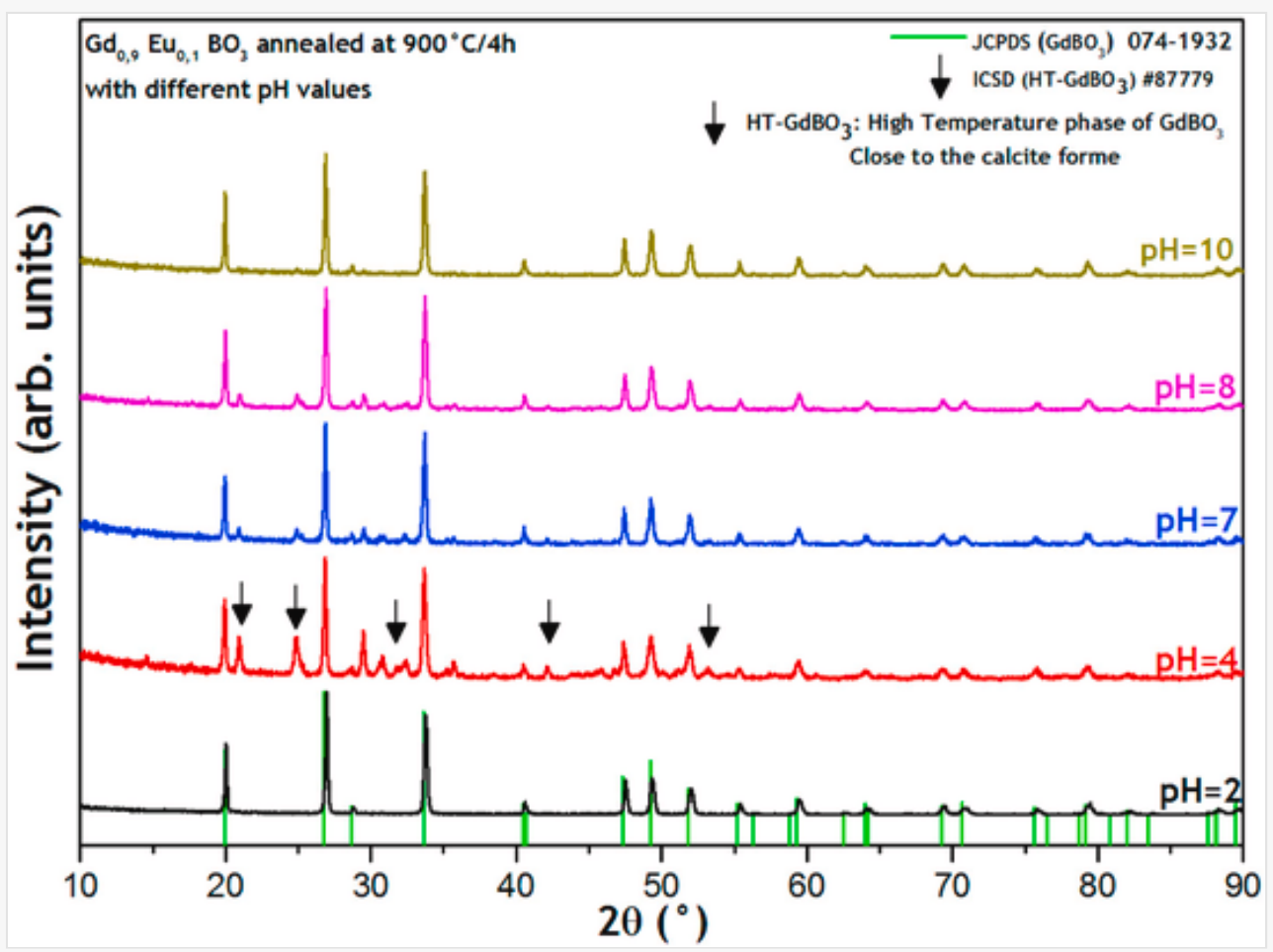

XRD patterns of $\mathrm{Gd}_{0.9} \mathrm{Eu}_{0.1} \mathrm{BO}_{3}$ with different $\mathrm{pH}$ value of precursor suspension, annealed at $900{ }^{\circ} \mathrm{C}$ for $4 \mathrm{~h}$ synthesized by aqueous sol-gel route.

The Rietveld analysis was used to accurately determine the structure and the crystallographic parameters by using Fullproof suite program for all samples as indicated in Fig. 2(c). On this figure we indicate the calculated and observed diffraction profile of $\mathrm{GdBO}_{3}$ doped at $10 \mathrm{at} \% \mathrm{Eu}^{3+}$ at $\mathrm{pH}=10$ delivered by the Rietveld refinements as example in hexagonal $P 6_{3} / m m c$ space group. The line $\mathrm{Y}_{\text {obs }}-\mathrm{Y}_{\text {calc }}$ represents the difference between the calculated and observed intensity. The crystallographic data and atomic parameters for $\mathrm{GdBO}_{3}$ doped at 10 at $\% \mathrm{Eu}^{3+}$ at $\mathrm{pH}=10$ are summarized in Table 1 . The crystal lattice strain generated by the annealing temperature is determined from the Williamson-Hall (W-H) relationship [35]:

$$
\beta \times \frac{\cos \theta}{\lambda}=\frac{1}{D}+\eta \sin \theta / \lambda
$$

Where $\beta$ is the full width at half maximum, $\lambda$ is the $X$-ray wavelength, $\theta$ is the diffraction angle, $D$ is the effective crystallite size and $\eta$ is the effective strain. In Fig. 3(a) and Fig. 3(b), we present the variation of the crystallite size as well as the strain quantities against the $\mathrm{Eu}^{3+}$ ion content (Fig. 3(a)) and pH value (Fig. 3(b)) in $\mathrm{GdBO}_{3}$ host material. At 10 at $\% \mathrm{Eu}^{3+}$, the sample presents the biggest crystallite size. From Fig. 3(a), it is observed that the below $10 \% \mathrm{~mol} \mathrm{Eu}^{3+}$, both crystallite size and strain increases from 0.5 to $10 \% \mathrm{~mol}$, after that they evolve in the opposite direction. The strain follows the same behavior than that of grain size. Both crystallite size and strain behaviors can relate to the phase parasites in addition to the defects, which can exist in the samples. Furthermore, with the variation of $\mathrm{pH}$ value of solution the $\mathrm{GdBO}_{3}: 10 \% \mathrm{~mol} \mathrm{Eu}{ }^{3+}$ crystallite size change (Fig. 3(b)). The crystallite size increases from $\mathrm{pH}=2$ to $\mathrm{pH}=4$ and decreases after from $\mathrm{pH}=4$ to $\mathrm{pH}=10$. Although that the sample with $\mathrm{pH}=4$ presents some parasite phase (Fig. 3(b)) it exhibits the biggest crystallite size and with the highest strain value. 


\section{Fig. 2(c)}

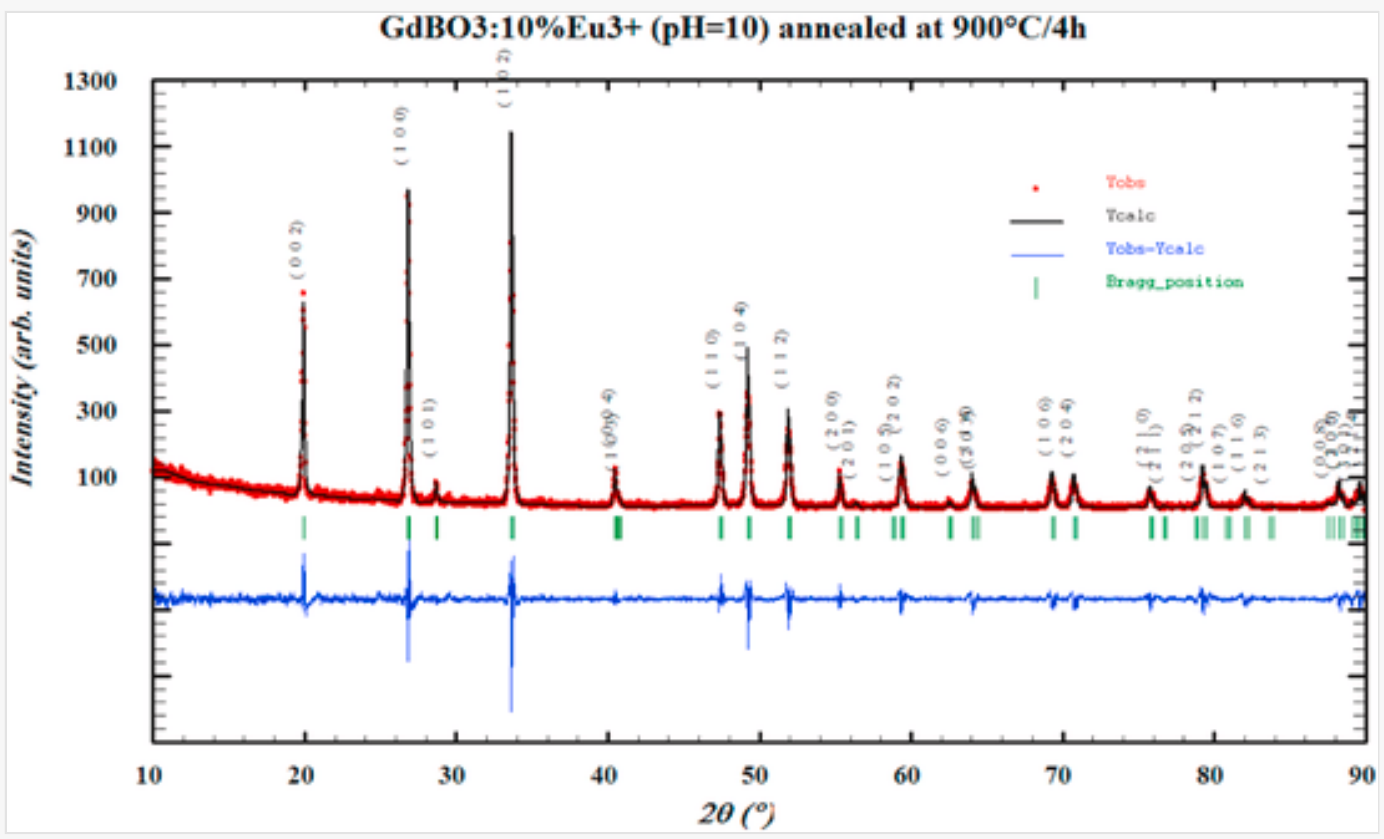

The Rietveld profile fits of X-Ray diffraction data of $\mathrm{Gd}_{0.9} \mathrm{Eu}_{0.1} \mathrm{BO}_{3}(\mathrm{pH}=10)$, annealed at $900{ }^{\circ} \mathrm{C}$ for $4 \mathrm{~h}$.

alt-text: Table 1

Table 1

(i) The table layout displayed in this section is not how it will appear in the final version. The representation below is solely purposed for providing corrections to the table. To preview the actual presentation of the table, please view the Proof.

Final refined structure parameters of $\mathrm{GdBO}_{3}: \mathrm{Eu}^{3+}$ samples using derived from the FullProf refinement of X-ray diffraction data.

\begin{tabular}{|c|c|}
\hline Chemical formula & $\mathrm{GdBO}_{3}$ \\
\hline Crystalsystem & Hexagonal \\
\hline Space group & $P 6_{3} / m m c$ \\
\hline $\mathrm{a}\left(\mathrm{A}^{\circ}\right)=\mathrm{b}\left(\mathrm{A}^{\circ}\right)$ & $3.8326(6)$ \\
\hline$c\left(A^{\circ}\right)$ & $8.909(2)$ \\
\hline $\mathrm{V}\left(\AA^{3}\right)$ & 113.33 \\
\hline Crystallite size (nm) & 74 \\
\hline $\mathrm{R}_{\exp } \%$ & 26.91 \\
\hline $\mathrm{R}_{\mathrm{wp} \%}$ & 36.6 \\
\hline $\mathrm{Rp} \%$ & 39.4 \\
\hline$\chi^{2}$ & 1.85 \\
\hline
\end{tabular}




\section{Fig. 3(a)}

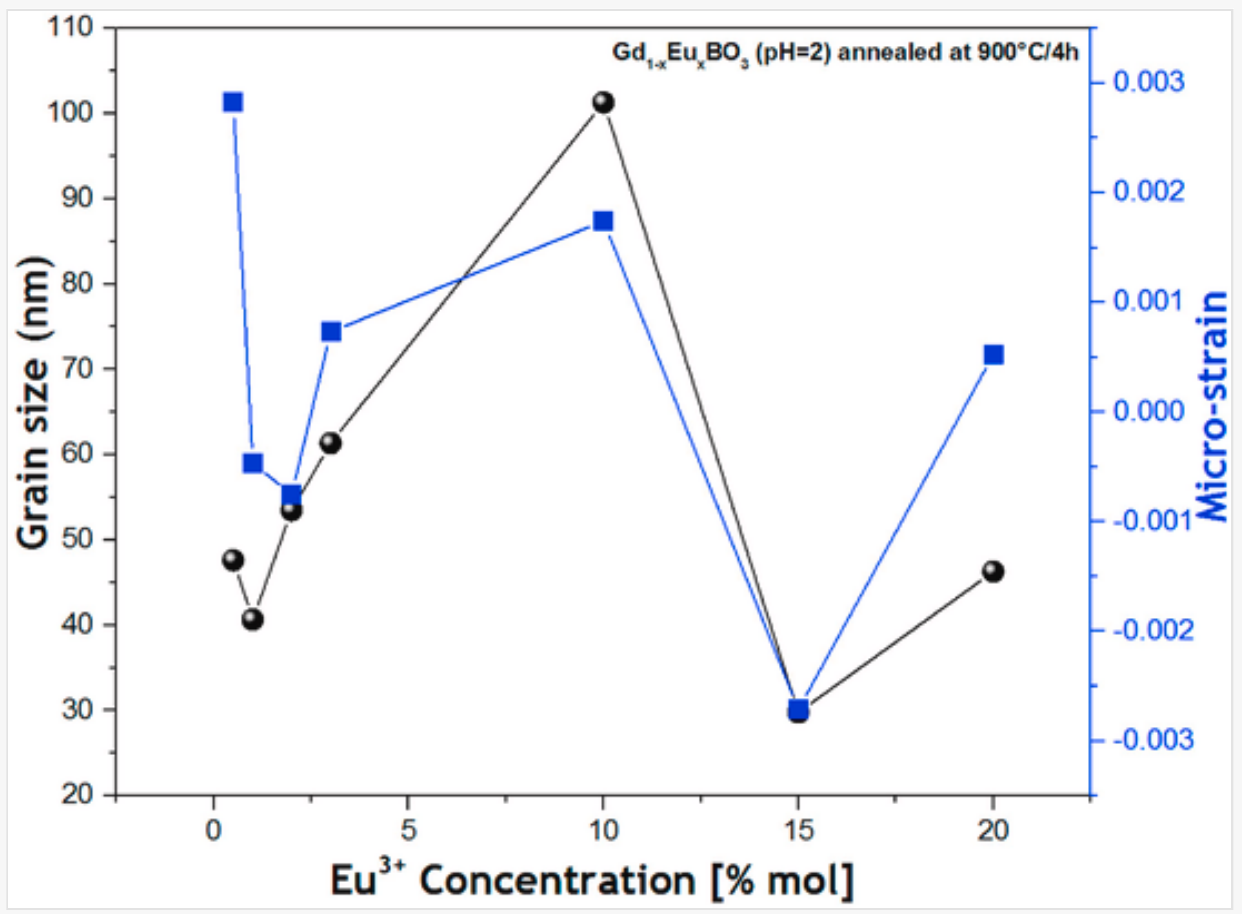

Crystallite size and microstrain evolutions of $\mathrm{Gd}_{1-\mathrm{x}} \mathrm{Eu}_{\mathrm{x}} \mathrm{BO}_{3}(\mathrm{pH}=2)$ powders, annealed at $900{ }^{\circ} \mathrm{C} / 4 \mathrm{~h}$

alt-text: Fig. 3(b)

\section{Fig. 3(b)}

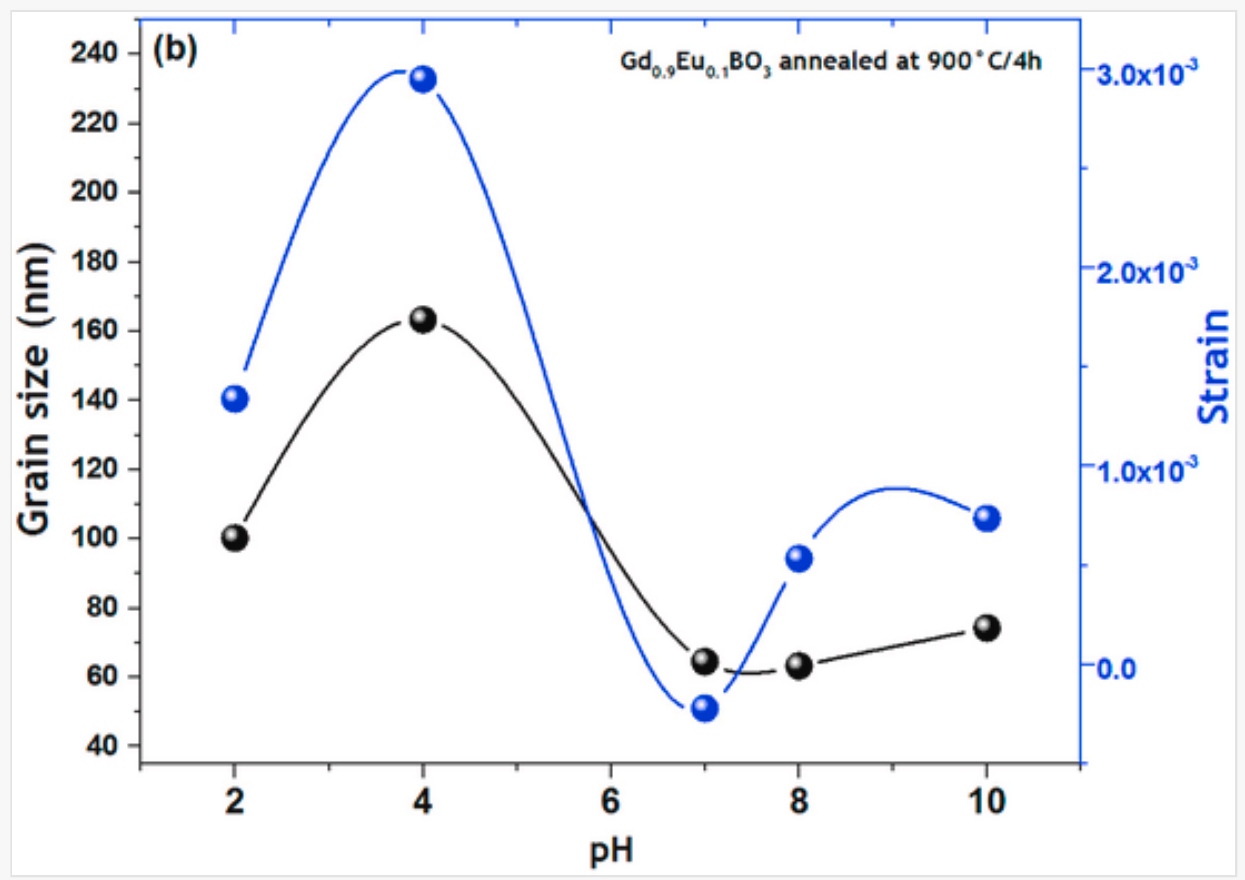

Crystallite size and microstrain evolutions of $\mathrm{Gd}_{0.9} \mathrm{Eu}_{0.1} \mathrm{BO}_{3}$ powders with different $\mathrm{pH}$ value of precursors suspension, annealed at $900^{\circ} \mathrm{C} / 4 \mathrm{~h}$

Also, from Fig. 3(a) and (b), it is important to note, the existence of some experimental points coming out of the curves, located principally for the $\mathrm{Eu}^{3+}$ ion weak and high concentrations as well as the high $\mathrm{pH}$ values. One 
can think that these points can be related to the purity of the $\mathrm{GdBO}_{3}$ vaterite phase, especially for the $\mathrm{Eu}^{3+}$ ion concentration parameter.

\subsection{Thermal analysis}

Thermogravimetric curve of $\mathrm{GdBO}_{3}: 10$ at $\% \mathrm{Eu}^{3+}$ for $\mathrm{pH}=10$ precursor pointed in blue in Fig. 4 consists in three mass losses regions. The first mass loss was observed between $80^{\circ} \mathrm{C}$ and $210{ }^{\circ} \mathrm{C}$ and is attributed to the elimination of absorbed species, such as alcohol molecules or water. The second important mass loss observed between $210{ }^{\circ} \mathrm{C}$ and $300{ }^{\circ} \mathrm{C}$, corresponds to $\mathrm{GdBO} 3$ condensation step, and is in parallel with a large endothermic peak (around $282{ }^{\circ} \mathrm{C}$ ) in the DTA curve. This endothermic effect is attributed to the removal of $\mathrm{H} 2 \mathrm{O}$ molecules. Otherwise, in the range of $210{ }^{\circ} \mathrm{C}$ to $300{ }^{\circ} \mathrm{C}$, there is formation of inorganic compounds. A third observed mass loss is between $300^{\circ}$ and to $490{ }^{\circ} \mathrm{C}$ depending on the formation of GdBO3 and corresponds to the first $\mathrm{GdBO} 3$ crystallization temperature range. This final mass loss is characteristic of ultimate formation of the crystallites growth of the $\mathrm{GdBO} 3$ network and final disposal of residual $\mathrm{OH}$ groups. Above $600{ }^{\circ} \mathrm{C}$, no weight loss was observed. It may be noted that the total mass loss is large (almost -91\%) occurred during the heat treatment to $600{ }^{\circ} \mathrm{C}$. From the recorded curves, we can deduce that the best crystallization temperatures, which were chosen, should be in excess of $1000^{\circ} \mathrm{C}$. The formation of hexagonal structure GdBO3 is observed above $600{ }^{\circ} \mathrm{C}$, which is also seen in the curve of the DTA as a nearly linear and stable curve between $600{ }^{\circ} \mathrm{C}$ and $1100^{\circ} \mathrm{C}$.

alt-text: Fig. 4

Fig. 4

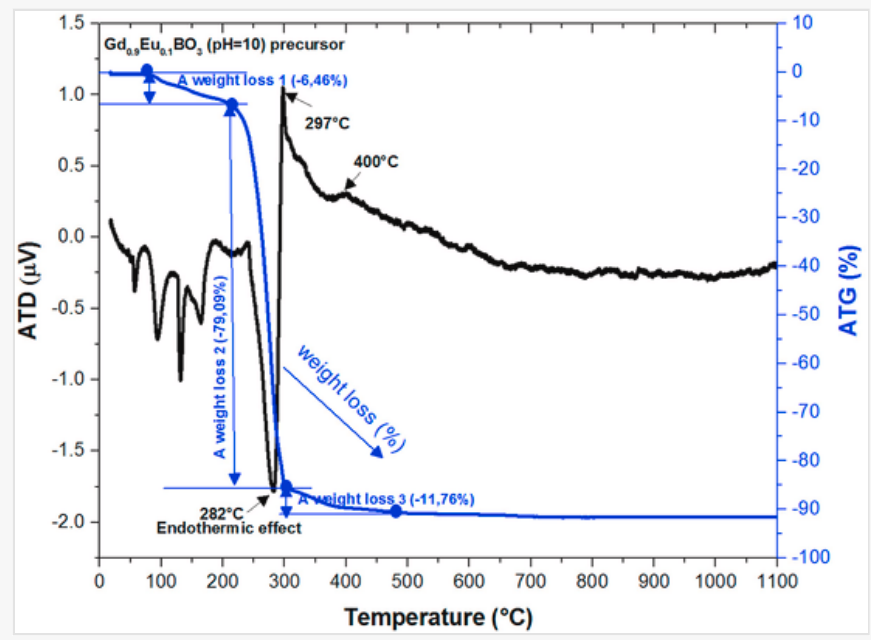

Thermogravimetric analysis of $\mathrm{Gd}_{0.9} \mathrm{Eu}_{0.1} \mathrm{BO}_{3}(\mathrm{pH}=10)$ synthesized by aqueous sol-gel route.

\subsection{Morphology analysis}

It is well known that the morphology and particle size of the phosphors are important for their in lighting devices applications. In Fig. 5 we show that the morphology and particle size of the GdBO3: 10 at $\% \mathrm{Eu}^{3+}$ for $\mathrm{pH}=10$ powder for different $\mathrm{pH}$ value. From this figure, one can see that the morphology and size of the particles were dependent on the $\mathrm{pH}$ values. In fact, one can observe that the particles are slackly bound and connected to each other as networks with the particle size depend on the $\mathrm{pH}$ value. Indeed, for low $\mathrm{pH}=2$ the sample presents a small particle size, and slightly increases for $\mathrm{pH}=4$ and 8 . The sample prepared with $\mathrm{pH}=10$ exhibit a large particle size. Although, the crystallite size at $\mathrm{pH}=10$ is small, it has the largest particle size. The sizes of these primary particles were estimated about 150 and $250 \mathrm{~nm}$, which can be considered as the agglomeration of three 
to five crystallites estimated by $\mathrm{W}-\mathrm{H}$ method [36]. EDAX analysis, clarifies the qualitative analysis of the elements of the respective phosphor composition i.e. $\mathrm{Gd}^{3+}, \mathrm{Eu}^{3+}$ and $\mathrm{O}^{2-}$. Furthermore, EDAX spectra elucidate the absence of any impurity elements, during sol gel reaction (Fig. 5).

\section{alt-text: Fig. 5}

Fig. 5
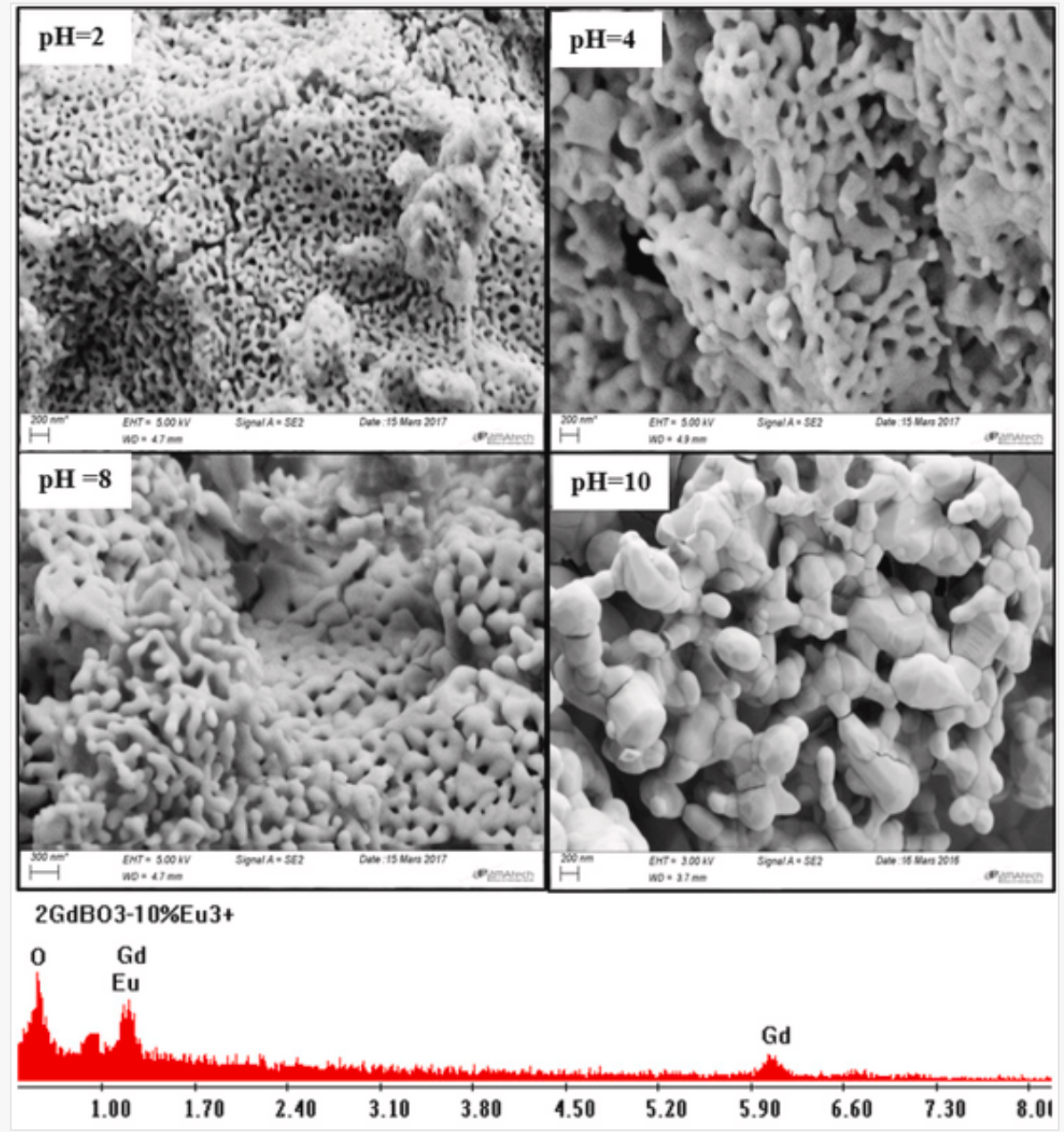

SEM morphology of $\mathrm{Gd}_{0.9} \mathrm{Eu}_{0.1} \mathrm{BO}_{3}(\mathrm{pH}=2,4,8$ and 10$)$ powders, annealed at $900{ }^{\circ} \mathrm{C} / 4 \mathrm{~h}$ synthesized by aqueous sol-gel route.

\subsection{Vibrational analysis}

It is well known that the trivalent rare-earth orthoborates presents three-isostructural forms, which are calcite, aragonite, or vaterite. Depending on the size of lanthanide cations, their orthoborates usually present the aragonite-type $(\mathrm{La}-\mathrm{Nd})$, vaterite-type $(\mathrm{Sm}-\mathrm{Yb})$, or calcite-type $(\mathrm{Lu})$ structure Furthermore, both two structures calcite-type and the aragonite-type take part triangular planar $\left(\mathrm{BO}_{3}\right)^{3-}$ groups, but the vaterite-type borates participate $\left(\mathrm{B}_{3} \mathrm{O}_{9}\right)^{9-}$ groups. Thereby, the vibrational spectra of vaterite orthoborates type are found to be significantly different from those of calcite and aragonite types. Fig. 6(a) shows the FT-IR spectra of $\mathrm{Gd}_{1-}$ ${ }_{x} \mathrm{Eu}_{\mathrm{x}} \mathrm{BO}_{3}\left(\mathrm{x}=0.005,0.01,0.02,0.03,0.1,0.15,0.2, \mathrm{pH}=2\right.$ and $15 \%$ excess of $\left.\mathrm{H}_{3} \mathrm{BO}_{3}\right)$ annealed at $900{ }^{\circ} \mathrm{C}$ for $4 \mathrm{~h}$.As a first observation, the absorption bands and peaks of the water $\left(\mathrm{H}_{2} \mathrm{O}\right)$ and $\mathrm{OH}$ molecules are absent. At low value of $(\mathrm{pH}=2)$, the reaction is governed by $\left(\mathrm{H}_{3} \mathrm{O}^{+}\right)$ionic molecules in the solution and the reaction $\mathrm{H}_{2} \mathrm{O}+\mathrm{H}^{+} \rightarrow \mathrm{H}_{3} \mathrm{O}^{+}$reduce the amount of the water in the final product [37]. Furthermore, one can observe that the FTIR vibrational spectra reflect the XRD analysis results. For all $\mathrm{Eu}^{3+}$ content, the samples exhibit the absorption bands in the region. $666-12250 \mathrm{~cm}^{-1}$, ascribed to the characteristic vibration modes of $\left(\mathrm{B}_{3} \mathrm{O}_{9}\right)^{9-}$ 
groups in the $\mathrm{GdBO}_{3}$ vaterite orthoborates [12,38,and39]]. The absorption intensity depends on $\mathrm{Eu}^{3+}$ concentration, which is related to the structure purity. In fact, for low $\mathrm{Eu}^{3+}$ content the samples present intense vibrational absorption, however, for high concentration (15 and 20 at $\%$ of $\mathrm{Eu}^{3+}$ ) weak absorption. This difference can be related to the presence of phase impurity in $\mathrm{GdBO}_{3}$ vaterite structure, generated by the high $\mathrm{Eu}^{3+}$ concentration. Furthermore, an intense absorption bands in $1225-1500 \mathrm{~cm}^{-1}$ region is observed for all sample except 10 at $\% \mathrm{Eu}^{3+}$. This band can be related to the asymmetric stretching of $\mathrm{B}-\mathrm{O}$ in triangular $\left(\mathrm{BO}_{3}\right)^{3-}$ groups in the calcite-type, with the analogy of FTIR spectra of calcite $\mathrm{LuBO}_{3}$ orthoborates [38]. The FTIR spectra analysis shows that it exist some boron atoms are in 3-fold coordination and the $\mathrm{GdBO}_{3}: \mathrm{Eu}^{3+}$ structure made of the $\left(\mathrm{BO}_{3}\right)^{3-}$ groups. To confirm the presence of $\mathrm{GdBO}_{3}$ orthoborates in other structure together with vaterite type, two Raman spectra was registered (Fig. 6(b)) for the two $\mathrm{Eu}^{3+}$ content namely 3 and 10 at \%. In fact, for 3 at $\% \mathrm{Eu}^{3+}$ the sample holds the parasite phase and for 10 at $\% \mathrm{Eu}^{3+}$ is pure. As shown in Fig. 6(b) for 10 at $\% \mathrm{Eu}^{3+}$ content (red color) the Raman spectrum correspond to pure $\mathrm{GdBO}_{3}$ vaterite structure [39]. The sample contains 3 at $\% \mathrm{Eu}^{3+}$ presents some additional peaks mainly an intense one at $951.07 \mathrm{~cm}^{-1}$ and some wreaks in $280-380 \mathrm{~cm}^{-1}$ region related to $\left(\mathrm{BO}_{3}\right)^{3-}$ groups [39].

alt-text: Fig. 6(a)

\section{Fig. 6(a)}

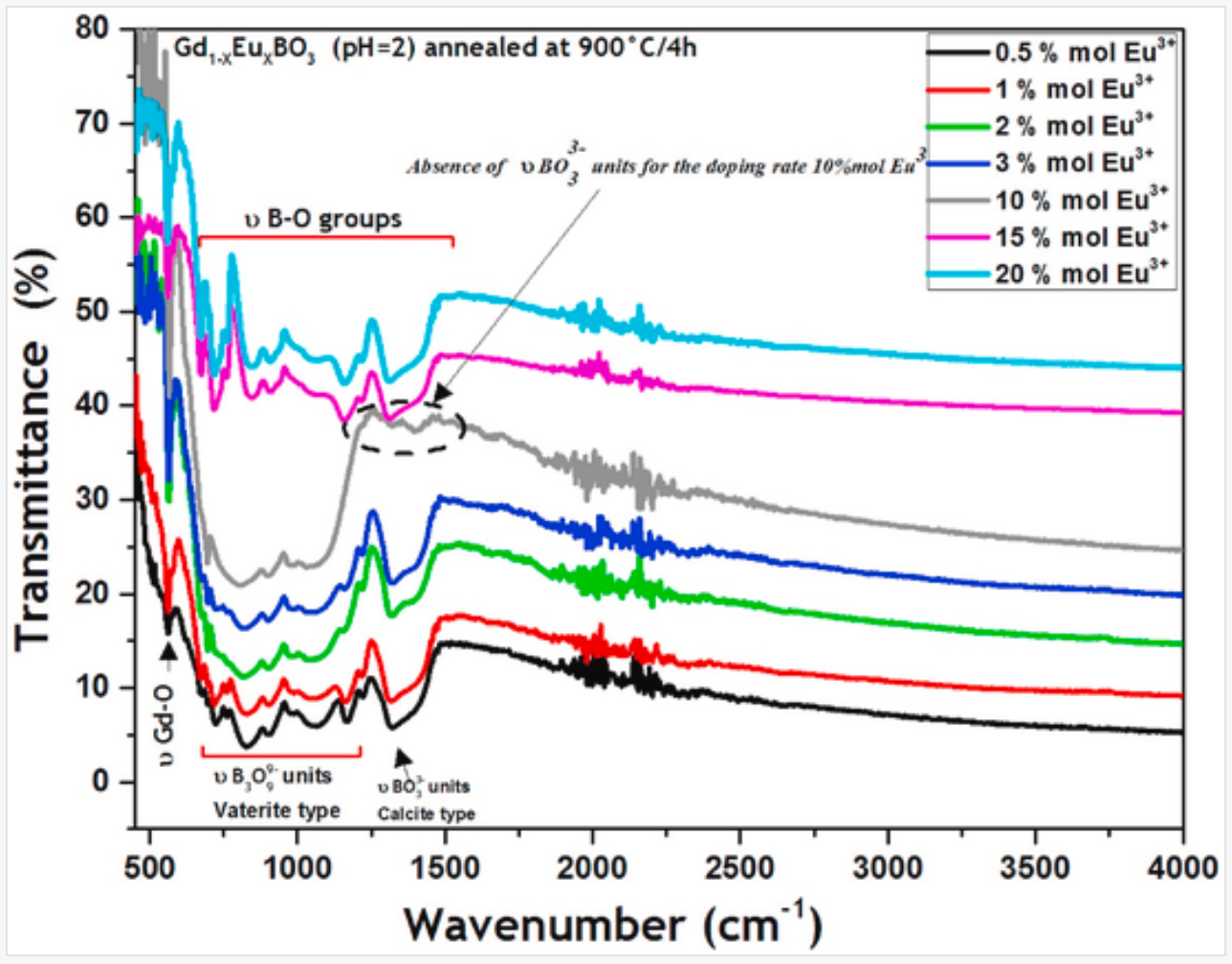

FTIR spectra of $\mathrm{Gd}_{1-\mathrm{x}} \mathrm{Eu}_{\mathrm{X}} \mathrm{BO}_{3}(\mathrm{pH}=2)$ annealed at $900^{\circ} \mathrm{C}$ for $4 \mathrm{~h}$, synthesized by aqueous sol-gel route. 


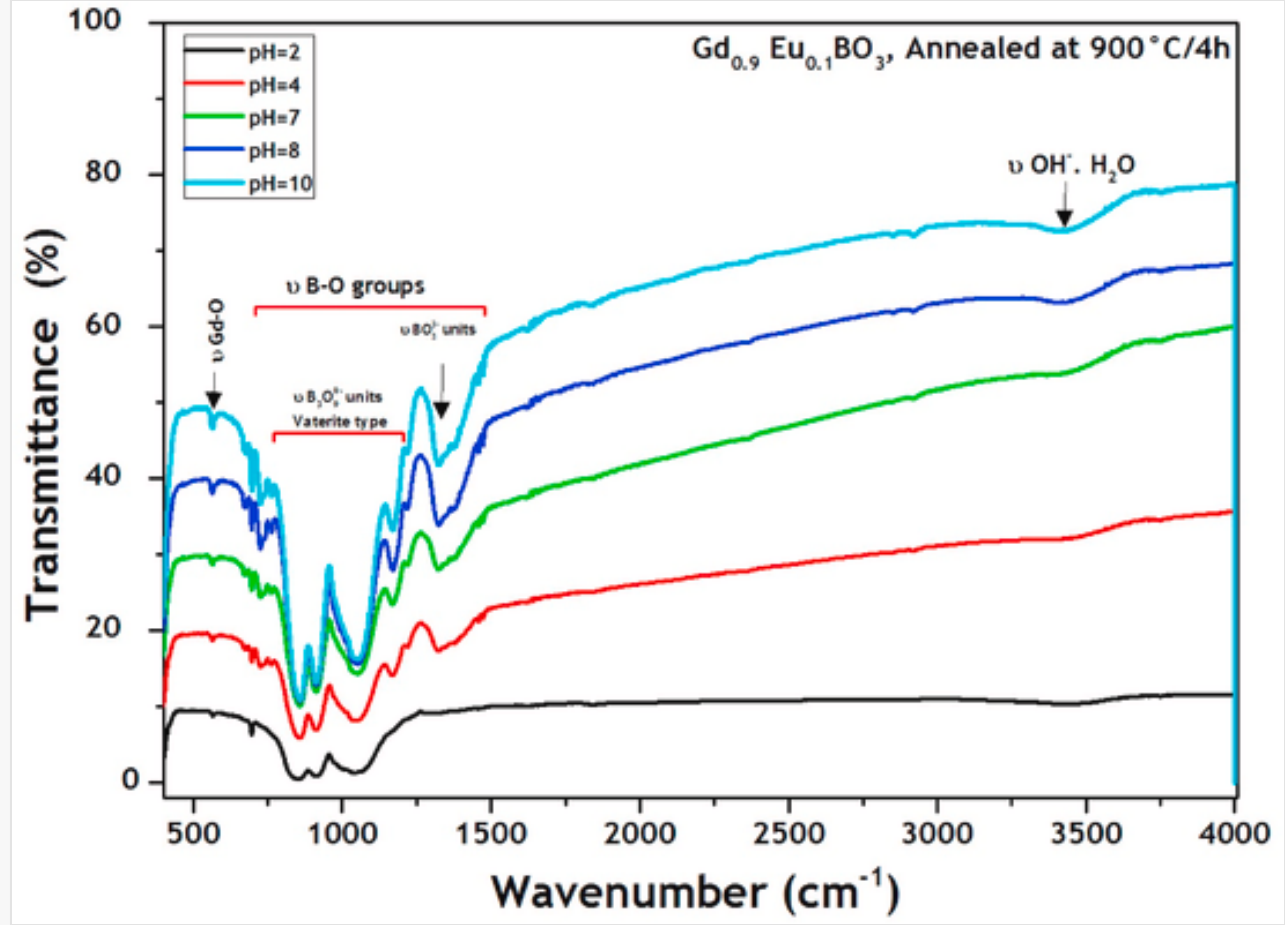

FTIR spectra of $\mathrm{Gd}_{0.9} \mathrm{Eu}_{0.1} \mathrm{BO}_{3}$ with different $\mathrm{pH}$ value of precursors suspension, annealed at $900{ }^{\circ} \mathrm{C}$ for $4 \mathrm{~h}$, synthesized by aqueous sol-gel route.

\subsection{Photoluminescence spectroscopy}

At the beginning, we have measured the room temperature emission spectra of $\mathrm{Gd}_{1-\mathrm{x}} \mathrm{Eu}_{\mathrm{x}} \mathrm{BO}_{3}(\mathrm{x}=0.005,0.01$, $0.02,0.03,0.1,0.15,0.2, \mathrm{pH}=2$ and $15 \%$ excess of $\mathrm{H}_{3} \mathrm{BO}_{3}$ ), annealed at $900{ }^{\circ} \mathrm{C}$ for $4 \mathrm{~h}$ duration, under $235 \mathrm{~nm}$ excitation wavelength (Charge transfer Band CTB) shown in Fig. 7(a). The spectra consist of sharp peaks ranging from 570 to $660 \mathrm{~nm}$ assigned the transitions from the excited ${ }^{5} \mathrm{D}_{0}$ level to the ground states of ${ }^{7} \mathrm{~F}_{\mathrm{J}}$ $(\mathrm{J}=1,2$ and 3$)$ of the $\mathrm{Eu}^{3+}$ activator [40]. The major emission transitions are centered at $591 \mathrm{~nm}\left({ }^{5} \mathrm{D}_{0} \rightarrow{ }^{7} \mathrm{~F}_{1}\right)$, orange-red magnetic dipole (MD) and at $614,624 \mathrm{~nm}\left({ }^{5} \mathrm{D}_{0} \rightarrow{ }^{7} \mathrm{~F}_{2}\right)$, which is the hypersensitive red electric dipole (ED). The weak peaks observed at 648 and $671 \mathrm{~nm}$ are ascribed to ${ }^{5} \mathrm{D}_{0} \rightarrow{ }^{7} \mathrm{~F}_{3}$. The less intense emission peak at $578 \mathrm{~nm}$ is attributed to ${ }^{5} \mathrm{D}_{0} \rightarrow{ }^{7} \mathrm{~F}_{0}$ forbidden transition. No intraconfigurationnel emission transitions from the highest excited states ${ }^{5} \mathrm{D}_{\mathrm{J}(\mathrm{J}=1-4)}$ of $\mathrm{Eu}^{3+}$ or $\mathrm{Gd}^{3+}$ are observed. Furthermore, it is observed from Fig. 7 (a), the orange emission corresponding to the ${ }^{5} \mathrm{D}_{0} \rightarrow{ }^{7} \mathrm{~F}_{1}$ magnetic dipole transition $(591 \mathrm{~nm})$ is greater than the red electric dipole transitions in the region $\left({ }^{5} \mathrm{D}_{0} \rightarrow{ }^{7} \mathrm{~F}_{2}\right.$ situated at $614 \mathrm{~nm}$ and $\left.624 \mathrm{~nm}\right)$ which is transitions from $\mathrm{Eu}^{3+}$ ions located in a non-inversion symmetry site. As shown in Fig. 7(a)inset, the concentration quenching occurs at $10 \mathrm{~mol} \%$ of $\mathrm{Eu}^{3+}$ ions concentration, which is associated with the energy transfer, occurs from one $\mathrm{Eu}^{3+}$ ions to other ions and finally quenches the emission intensity [41]. Two effects can tuned the orange-red $\mathrm{Eu}^{3+}$ emission: (i) the existence of parasitic phases and the type of symmetry in which $\mathrm{Eu}^{3+}$ is located (centrometric or non-centrometric), (ii) the change in crystallite size. In fact, the reduction of size into nanoscale which increase the number of $\mathrm{Eu}^{3+}$ ions located in the surface area, leading to lowering the symmetry of crystal field and thereby increases the red emission $\left({ }^{5} \mathrm{D}_{0} \rightarrow{ }^{7} \mathrm{~F}_{2}\right)$ relative to the orange one $\left({ }^{5} \mathrm{D}_{0} \rightarrow{ }^{7} \mathrm{~F}_{1}\right)$. Therefore, the asymmetry ratio parameter $\mathrm{R}$, which is the ratio of the integrated intensities of the luminescence transitions of ${ }^{5} \mathrm{D}_{0} \rightarrow{ }^{7} \mathrm{~F}_{2}$ on ${ }^{5} \mathrm{D}_{0} \rightarrow{ }^{7} \mathrm{~F}_{1}$ transitions, is introduced (Fig. 7(b)) [42,43]. In fact, this parameter can give 
information about the $\mathrm{Eu}^{3+}$ ions local symmetry distortion in the host material. In addition, as a consequence of nanoscale materials, the value of $\mathrm{R}$ parameter is usually higher for the nanoscale material relative to its bulk form. From Fig. 7(b), one can observe that as the $\mathrm{Eu}^{3+}$ concentration increases from 0.5 to 3 at $\% \mathrm{Eu}^{3+}$, the $\mathrm{R}$ parameter increases and roughly stabilized between 3 and 10 at $\% \mathrm{Eu}^{3+}$ to come back increases after that. The increasing in $\mathrm{R}$ parameter is related to the $\mathrm{Eu}^{3+}$ site symmetry lowering which can be generated by existence of parasite phases or defects. For the constant quasi-constant value of $\mathrm{R}$ is connected to the $\mathrm{GdBO}_{3}$ hexagonal phase purity. Although, this low symmetry can gives better chromaticity but with lower emission intensity.

alt-text: Fig. 7(a)

\section{Fig. 7(a)}

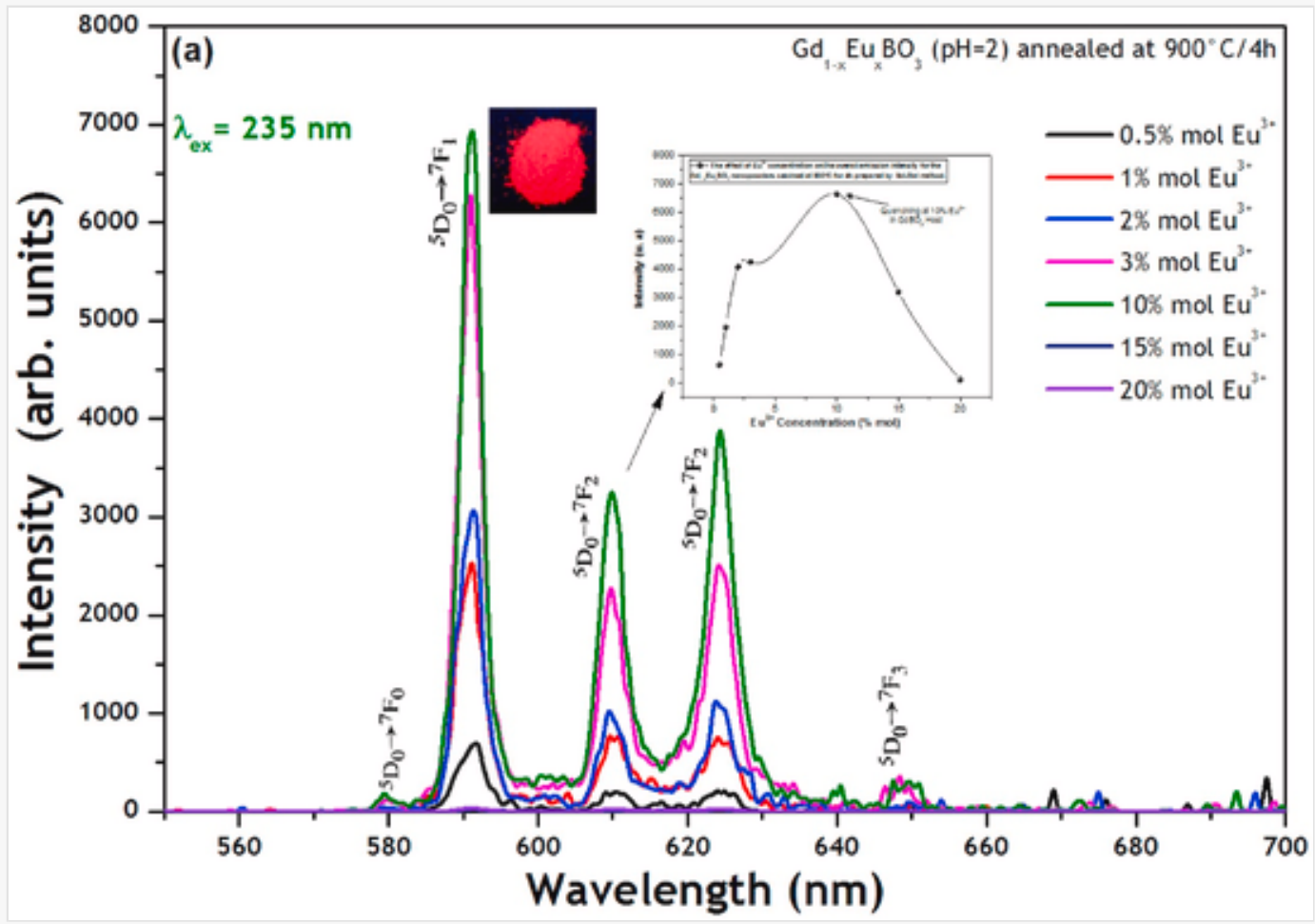

Emission spectra of $\mathrm{Gd}_{1-\mathrm{x}} \mathrm{Eu}_{\mathrm{X}} \mathrm{BO}_{3}(\mathrm{pH}=2)$ powders, annealed at $900{ }^{\circ} \mathrm{C} / 4 \mathrm{~h}$

alt-text: Fig. 7(b)

\section{Fig. 7(b)}

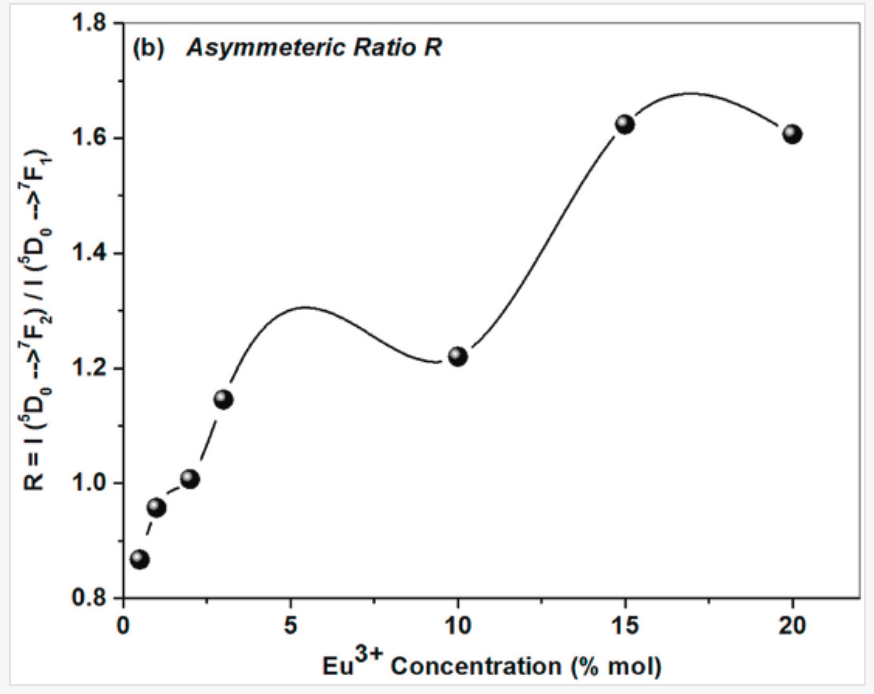


The room temperature excitation spectrum (Fig. 7(c)) of the $\mathrm{GdBO}_{3}: 10$ at $\% \mathrm{Eu}^{3+}$, annealed at $900{ }^{\circ} \mathrm{C}$ for $4 \mathrm{~h}$ was recorded by monitoring the emission peak at $614 \mathrm{~nm}$. Fig. 7 (c) reveals a broad and strong excitation band in the 200-265 nm range, which indicates the charge-transfer (CT) transition between $\mathrm{O}^{2-}$ and $\mathrm{Eu}^{3+}$. The weak excitation peak observed at $275 \mathrm{~nm}$ is assigned to the ${ }^{8} \mathrm{~S}_{7 / 2} \rightarrow{ }^{6} \mathrm{I}_{\mathrm{J}}$ transitions of $\mathrm{Gd}^{3+}$ ion. The presence of this peak indicates that it exist an energy transfer from $\mathrm{Gd}^{3+}$ to $\mathrm{Eu}^{3+}$ [44]. Several peaks from 300 to $540 \mathrm{~nm}$ (Fig. 7 (c) inset) are likely to have originated from the intra-4f forbidden transitions of $\mathrm{Eu}^{3+}$ ions. the excited $\mathrm{Gd}^{3+}$ states than the ${ }^{5} \mathrm{D}_{0}$ state of $\mathrm{Eu}^{3+}$; consequently, $\mathrm{Gd}^{3+}$ ions can be play an intermediate for the energy transfer and sensitize $\mathrm{Eu}^{3+}$ luminescence.

\section{alt-text: Fig. 7(c)}

Fig. 7(c)

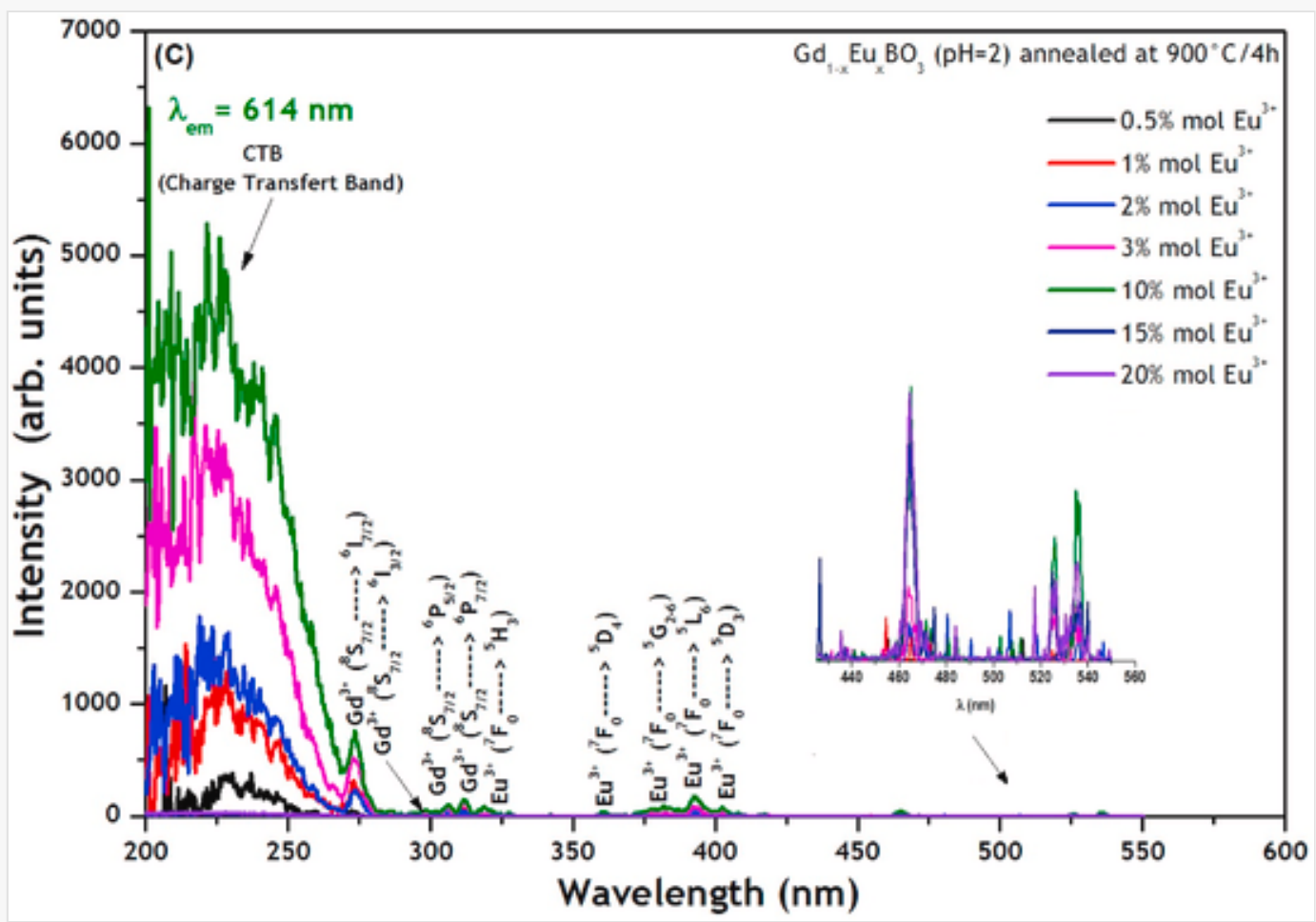

Excitation spectra of $\mathrm{Gd}_{1-\mathrm{x}} \mathrm{Eu}_{\mathrm{X}} \mathrm{BO}_{3}(\mathrm{pH}=2)$ powders, annealed at $900{ }^{\circ} \mathrm{C} / 4 \mathrm{~h}$

In fact, the charge-transfer (CT) transition process corresponds to the transfer of an electron from the $2 p$ orbitals of the oxygen ligands to the empty $4 \mathrm{f}$ orbitals of the $\mathrm{Eu}^{3+}$ ion, giving rise usually to the charge transfer band (CTB). In most cases, CTB exhibits a stronger intensity than that of the $4 \mathrm{f}-4 \mathrm{f}$ interconfigurational transitions that appearing as narrow peaks with low intensities in excitation spectra. It is known that this interconfigurational transition of type $\left(n p^{q}, 4 f^{6} \rightarrow n p^{q-1} 4 f^{7}\right)$ has a high absorption cross-section compared to that of $4 \mathrm{f}^{6}-4 \mathrm{f}^{6}$ intraconfigurationnel transitions, which explain difference in intensity between them on the excitation spectra. Also, this process can induce a significant luminescence of the dopant ion $\mathrm{Eu}^{3+}$ doped oxides material if the population of radiative levels ${ }^{5} \mathrm{D}_{\mathrm{J}}$ by a process of energy transfer is itself important [45].

The room temperature steady photoluminescence excitation and emission, of $\mathrm{GdBO}_{3}: 10$ at $\% \mathrm{Eu}^{3+}$, for different $\mathrm{pH}$ value of solution namely: $\mathrm{pH} 2,4,7,8$ and 10 annealed at $900{ }^{\circ} \mathrm{C}$ for $4 \mathrm{~h}$ duration were measured and displayed in Fig. 8(a and c). The emission spectra were measured under $235 \mathrm{~nm}$ excitation wavelength (Charge transfer Band (CTB)). The spectra show the characteristic features of $\mathrm{Eu}^{3+}$ emission, with orange ${ }^{5} \mathrm{D}_{0} \rightarrow{ }^{7} \mathrm{~F}_{1}$ 
transition domination. From Fig. $8(\mathrm{a})$, one can see that intensity of the observed orange-red ${ }^{5} \mathrm{D}_{0} \rightarrow{ }^{7} \mathrm{D}_{\mathrm{J}}$ transition emissions are influenced by the $\mathrm{pH}$ values of the solution. Indeed, with increasing the $\mathrm{pH}$ value from 2 to 4 , the intensity decreases and increases from 4 to reach the higher intensity at $\mathrm{pH}=10$ (Fig. 8(a) inset), despite the presence of the highest $\mathrm{H}_{2} \mathrm{O}$ absorption band in this sample (Fig. 6(c)), which quench usually the luminescence. The highest emission at $\mathrm{pH}=10$ compared to the other $\mathrm{pH}$ values can be explained by two ways: (i) the sample prepared at $\mathrm{pH}=10$ presents crystallite size among the smallest of the $\mathrm{pH}$ values (see Fig. 3(b)), which can leads the segregation of a large $\mathrm{Eu}^{3+}$ concentration ions on the surface of the crystallite, giving rise to the highest emission under UV $(235 \mathrm{~nm})$ excitation constituting the quenching concentration. (ii) Also, one can related this behavior to the structural purity, where the $\mathrm{Gd}_{0.9} \mathrm{Eu}_{0.1} \mathrm{BO}_{3}$ sample prepared at $\mathrm{pH}=10$ presents a vaterite quasi-pure structure.

alt-text: Fig. 8(a)

\section{Fig. 8(a)}

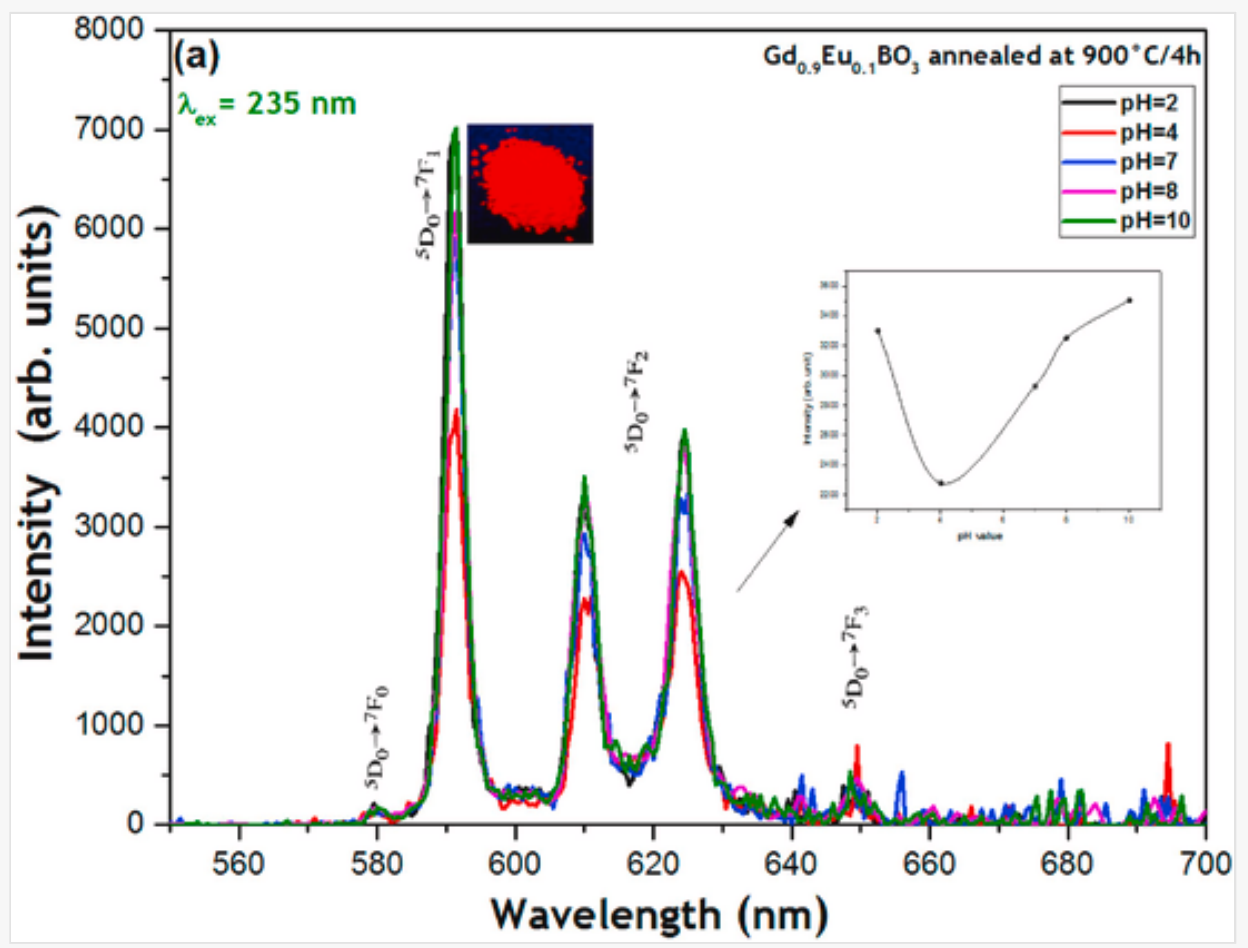

Emission spectra of $\mathrm{Gd}_{0.9} \mathrm{Eu}_{0.1} \mathrm{BO}_{3}$ powders with different $\mathrm{pH}$ value of precursors suspension, annealed at $900{ }^{\circ} \mathrm{C} / 4 \mathrm{~h}$.

alt-text: Fig. 8(b)

Fig. 8(b) 


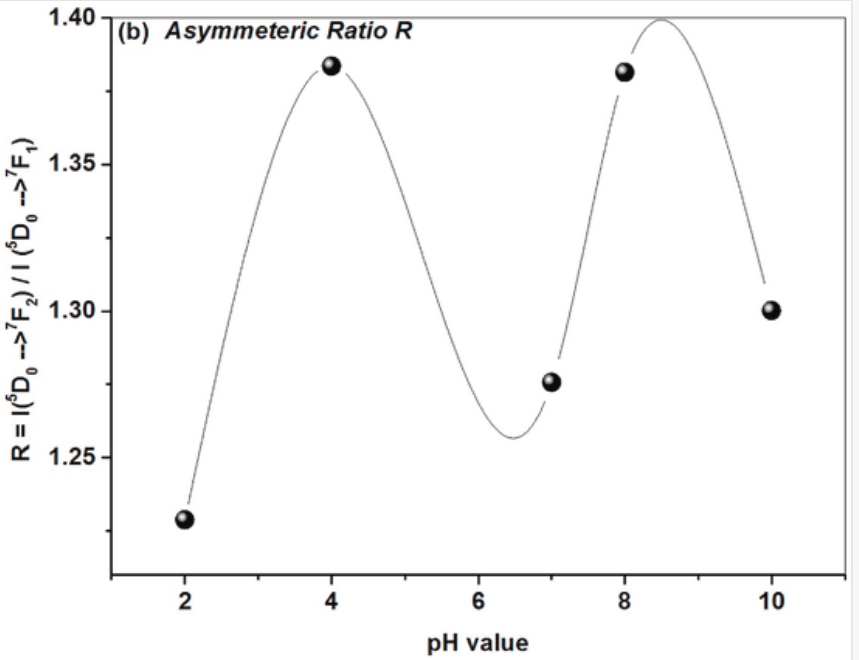

Asymmetry ratios for $\mathrm{Eu}^{3+}$ in $\mathrm{GdBO}_{3}$ with various $\mathrm{pH}$ value of precursors suspension.

\section{alt-text: Fig. 8(c)}

\section{Fig. 8(c)}

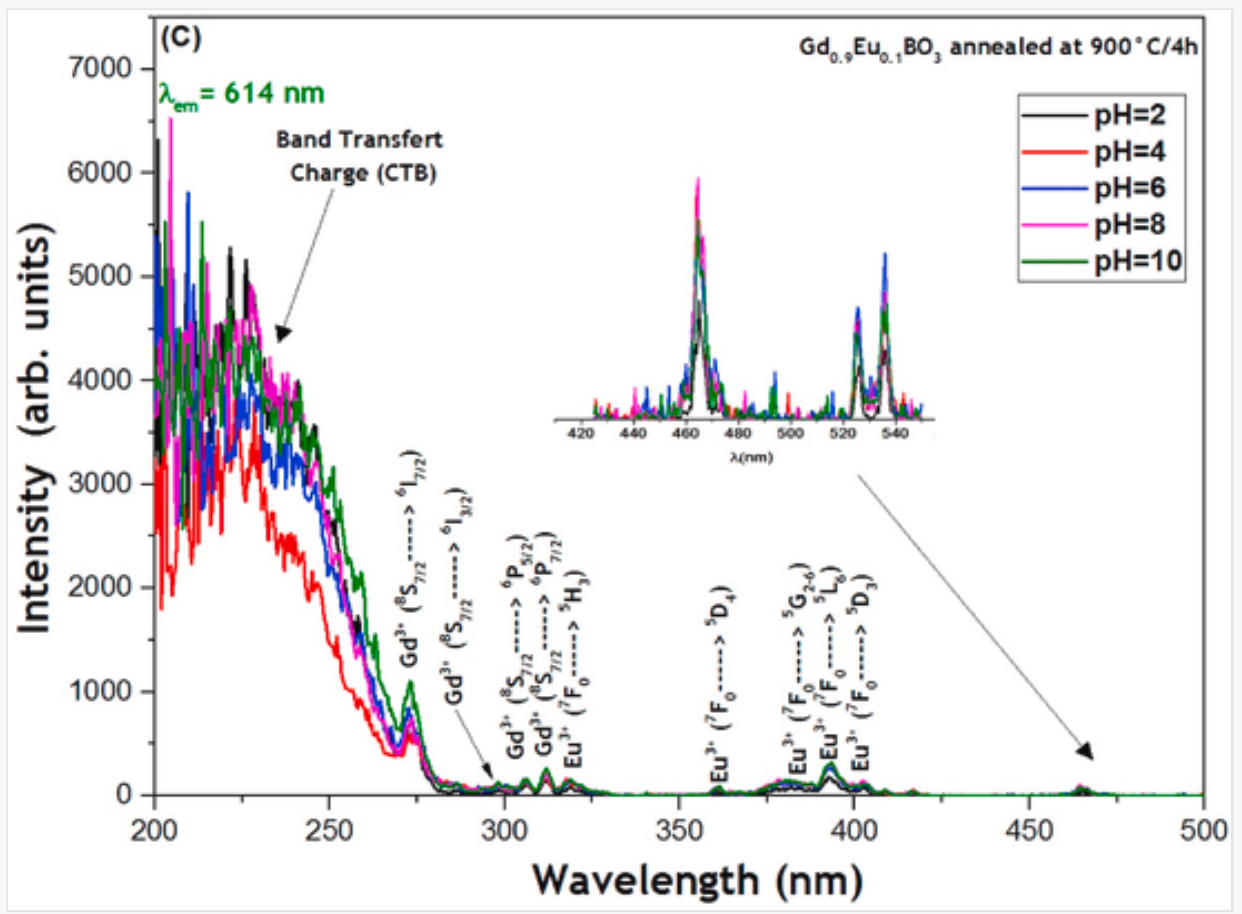

Excitation spectra of $\mathrm{Gd}_{0.9} \mathrm{Eu}_{0.1} \mathrm{BO}_{3}$ powders with different $\mathrm{pH}$ value of precursors suspension, annealed at $900{ }^{\circ} \mathrm{C} / 4 \mathrm{~h}$. 
The variation of the asymmetry ratio parameter $\mathrm{R}$ in function of $\mathrm{pH}$ value of solution is displayed in Fig. 8(b). The values of $\mathrm{R}$ do not follow a well-defined trend and presents like zigzag shape between $\mathrm{pH}$ values. We can think that the value of $\mathrm{R}$ is very sensitive to several parameters, which can be changed by switching from one $\mathrm{pH}$ to another following, and thus influencing the symmetry of the site occupied by the $\mathrm{Eu}^{3+}$ ion in $\mathrm{GdBO}_{3}$ host material. Also, from this figure, we can note that for some $\mathrm{pH}$ values we can promotes the ${ }^{5} \mathrm{D}_{0} \rightarrow{ }^{7} \mathrm{~F}_{2}$ red emission and can achieve better chromaticity, despite their lower luminescence compared to that $\mathrm{pH}=10$. Then, there is a tradeoff between the chromaticity and intensity of luminescence.

The excitation spectra for different $\mathrm{pH}$ value, annealed at $900{ }^{\circ} \mathrm{C}$ for $4 \mathrm{~h}$ were measured for the red emission $(614 \mathrm{~nm})$, and presented in Fig. 8(c). From this figure, the charge-transfer (CT) transition between $\mathrm{O}^{2-}$ and $\mathrm{Eu}^{3+}$ were observed between 200 and $265 \mathrm{~nm}$ in addition to $\mathrm{Gd}^{3+}$ excitation transition and those of intra-4f forbidden transitions (Fig. 8(c) inset) of $\mathrm{Eu}^{3+}$ ions.

Fig. 9(a) displays the room temperature time-resolved phosphorescence emission spectra of GdBO3:10 at $\%$ $\mathrm{Eu}^{3+}$, for $\mathrm{pH}=10$ annealed at $900{ }^{\circ} \mathrm{C}$ for $4 \mathrm{~h}$ duration as an example measured in phosphoresce mode. The extracted integrated photoluminescence decay curves of the ${ }^{5} \mathrm{D}_{0} \rightarrow{ }^{7} \mathrm{~F}_{1}(591 \mathrm{~nm})$ transition under UV excitation (CTB-235 nm) for different $\mathrm{Eu}^{3+}$ content and different $\mathrm{pH}$ value of solution is presented in Fig. 9(b) and Fig. 9 (c) respectively. Referring to the decay curves, the effective decay times $\left(\tau_{A V}\right)$, which is considered as the experimental lifetime $\left(\mathrm{t}_{\text {exp }}\right)$ for ${ }^{5} \mathrm{D}_{0}$ level of $\mathrm{Eu}^{3+}$ the can be determined using the following expression [33]:

$$
\tau_{A V}=\frac{\int_{0}^{+\infty} t I(t) d t}{\int_{0}^{+\infty} I(t) d t}
$$

Where $I(t)$ is the luminescence intensity at the considered time. The ${ }^{5} \mathrm{D}_{0}$ level lifetime as a function of $\mathrm{Eu}^{3+}$ concentration was presented in Fig. 9(b) inset. From Fig. 9(b) inset, one can observe that there are three regions with respect to the $\mathrm{Eu}^{3+}$ content. The first region situated between 0.5 and 2 at $\% \mathrm{Eu}^{3+}$, in which the ${ }^{5} \mathrm{D}_{0}$ level lifetime decreases. The second one from 2 to 10 at $\% \mathrm{Eu}^{3+}$, the ${ }^{5} \mathrm{D}_{0}$ level lifetime increases. The third last one, from 10 to $20 \mathrm{at}_{\% \mathrm{Eu}^{3+}}$ the lifetime decreases again. Several mechanisms could be used to explain the deceasing of ${ }^{5} \mathrm{D}_{0}$ luminescence lifetimes in these three regions. For the first and the third region, the reducing of the lifetime can be connected with cross-relaxation between the $\mathrm{Eu}^{3+}$ ions [46] and the existence of the parasitic phases, playing a quencher role. Indeed, the $\mathrm{Eu}^{3+}$ ions can interact in their excited states, and also, this interaction can happen between $\mathrm{Eu}^{3+}$ its excited state and $\mathrm{Eu}^{3+}$ neighboring ions in a ground state, which result in energy transfer and depopulation of $\mathrm{Eu}^{3+}$ ions in the ${ }^{5} \mathrm{D}_{0}$ state. For the third region, the increasing of the lifetime can be related to fact that $\mathrm{GdBO}_{3}$ becomes the more quasi-purest hexagonal vaterite structure and presents the biggest crystallite size with respect to $\mathrm{Eu}^{3+}$ concentration. 


\section{Fig. $9(\mathbf{c})$}

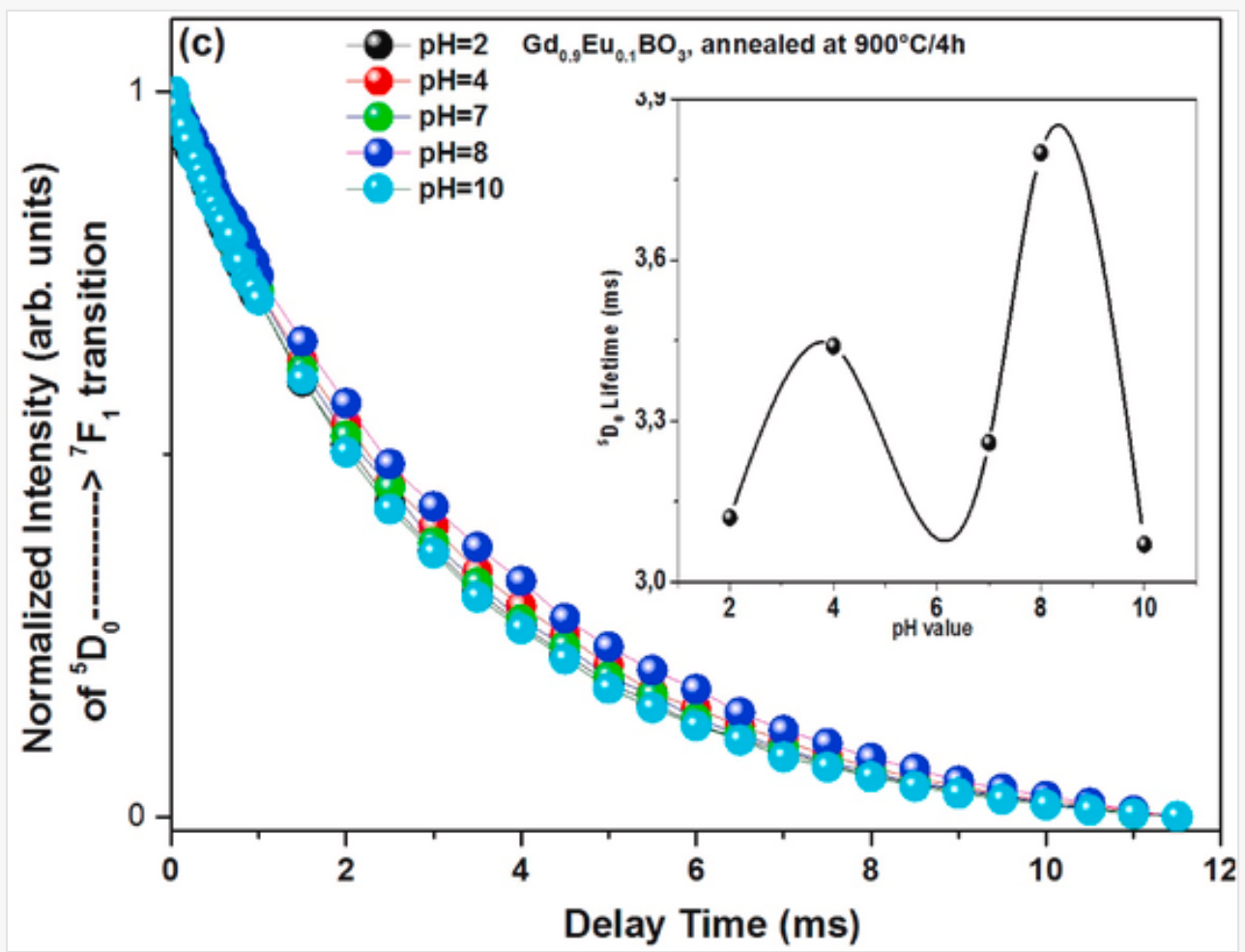

Delay time curves of ${ }^{5} \mathrm{D}_{0} \rightarrow{ }^{7} \mathrm{~F}_{1}$ transition of $\mathrm{Gd}_{0.9} \mathrm{Eu}_{0.1} \mathrm{BO}_{3}$ powders with different $\mathrm{pH}$ value of precursor suspension, annealed at $900^{\circ} \mathrm{C} / 4 \mathrm{~h}$.

From Fig. 9(c) inset, on can see variation that ${ }^{5} \mathrm{D}_{0}$ level lifetime depend strongly on the $\mathrm{pH}$ value of solution. In fact, the value of ${ }^{5} \mathrm{D}_{0}$ level lifetime connected to several related parameters such as the synthesized method, the phase purity, structure defects, atomic or molecular impurity in the host material and the crystallite size. Although $\mathrm{GdBO}_{3}: \mathrm{Eu}^{3+}$ samples prepared at $\mathrm{pH}=2$ and 10 present the purest hexagonal vaterite structure their ${ }^{5} \mathrm{D}_{0}$ level lifetime values are smallest compared to the intermediate $\mathrm{pH}$ values. One can think that the crystallite size is responsible this smallest lifetime. Indeed, for $\mathrm{pH}=10$ the sample presents the highest orange-red emission and a small crystallite size. Another possible cause is the presence the $\mathrm{H}_{2} \mathrm{O}$ absorbed band with high quantity at $\mathrm{pH}=10$, which quench the emission leading a shortness lifetime.

Furthermore, in nano-size optical materials, several parameters such as the structure, the size have an important impact on the radiative and nonradioactive lifetimes, energy transfer, and thermalization phenomena. In fact, it was found that rare earth doped nano-sized inorganic materials, can exhibits a prolonged lifetimes [47], which further explain the increases of the lifetime in the third region in Fig. 9(b) inset and the variation with respect of $\mathrm{pH}$ values.

In addition, for evaluating the performance of such $\mathrm{GdBO}_{3}: \mathrm{Eu}^{3+}$ nanophosphor, the chromaticity coordinate is one of the important parameters. Fig. 10 displays the color coordinates for $\mathrm{GdBO}_{3}: 10$ at $\% \mathrm{Eu}^{3+}$, for different $\mathrm{pH}$ value of solution. The CIE coordinates of the synthesized samples given in Table 2. It can be clearly seen from the figure and the table that most of the chromaticity coordinates are located in the orange-red region. In addition, One can that CIE coordinates are closer to the NTSC (National Television Systems Committee) value of red phosphors $(0.670,0.330)$ [48]. These results indicate that this kind of phosphor can be useful in the development of LEDs applications. 


\section{Fig. 10}

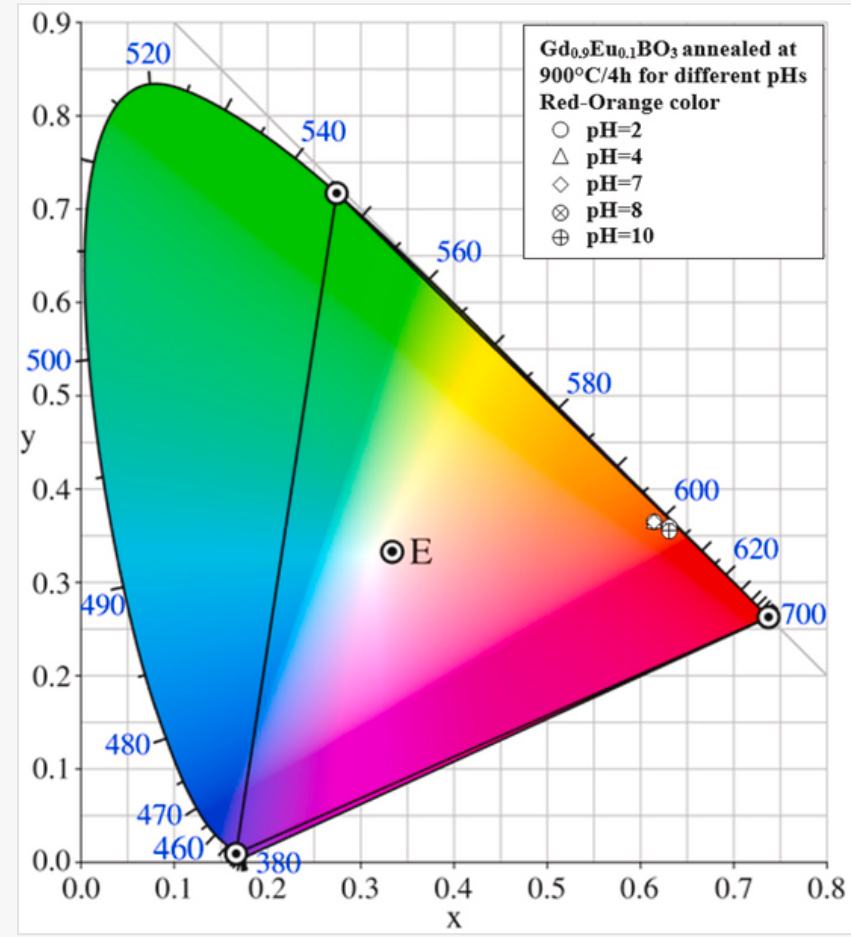

Chromaticity coordinates diagram at different $\mathrm{pH}$ values of precursors suspension of $\mathrm{Gd}_{0.9} \mathrm{Eu}_{0.1} \mathrm{BO}_{3}$ annealed at $900{ }^{\circ} \mathrm{C} / 4 \mathrm{~h}$

alt-text: Table 2

Table 2

(i) The table layout displayed in this section is not how it will appear in the final version. The representation below is solely purposed for providing corrections to the table. To preview the actual presentation of the table, please view the Proof.

(x,y)Chromaticity coordinates at different $\mathrm{pH}$ values of precursor suspension of $\mathrm{Gd}_{0.9} \mathrm{Eu}_{0.1} \mathrm{BO}_{3}$ annealed at $900{ }^{\circ} \mathrm{C} / 4 \mathrm{~h}$. The standard NTSC red color coordinates are presented in ref [48].

\begin{tabular}{|l|l|l|}
\hline \multirow{2}{*}{$\mathrm{pH}$ value } & \multicolumn{2}{|l|}{ CIE Coordinate } \\
\cline { 2 - 3 } & $\mathrm{x} \mathrm{y}$ & \\
\hline 2 & 0.6318 & 0.3678 \\
\hline 4 & 0.6334 & 0.3662 \\
\hline 7 & 0.6336 & 0.3660 \\
\hline 8 & 0.6361 & 0.3634 \\
\hline 10 & 0.6355 & 0.3641 \\
\hline NTSC & $\mathbf{0 . 6 7 0}$ & $\mathbf{0 . 3 3 0}$ \\
\hline
\end{tabular}

\section{Conclusion}


Intense orange-red emitting $\mathrm{GdBO}_{3}$ orthoborate based nanophosphors doped with $\mathrm{Eu}^{3+}$ ion have been successfully synthesized via simple and low-cost, using acetylacetone assisted aqueous sol-gel process. Systematic studies have been performed for different doping $\mathrm{Eu}^{3+}$ concentration and the $\mathrm{pH}$ value precursors suspension. It has been found that the $\mathrm{Eu}^{3+}$ ion content and $\mathrm{pH}$ value of solution have crucial influences on the structural, morphology and spectroscopic properties. The purest of the hexagonal $\mathrm{GdBO}_{3}$ vaterite structure is governed by $\mathrm{Eu}^{3+}$ concentration and $\mathrm{pH}$ values. $\mathrm{GdBO}_{3}$ sample prepared with $10 \% \mathrm{~mol} \mathrm{Eu}{ }^{3+}$ at $\mathrm{pH}=2$ present the purest $P 6_{3} / m m c$ hexagonal vaterite structure. Furthermore, the existence of $\left(\mathrm{BO}_{3}\right)^{3-}$ groups together with $\left(\mathrm{B}_{3} \mathrm{O}_{9}\right)^{9-}$ shown by vibrational analysis, is discussed and related to the $\mathrm{GdBO}_{3}$ calcite type or other vaterite structure namely triclinic and monoclinic. The crystallite size and morphology of the samples can be readily tailored by adjusting the $\mathrm{pH}$ and $\mathrm{Eu}^{3+}$ doping. Although, the crystallite size of $\mathrm{GdBO}_{3}: 10 \% \mathrm{~mol} \mathrm{Eu}^{3+}$ at $\mathrm{pH}=10$ is small, the corresponding particle size is largest. Under UV excitation (Charge Transfer Band (CTB)), all $\mathrm{Eu}^{3+}$-doped $\mathrm{GdBO}_{3}$ samples show orange-red emission lines corresponding to transitions originate only from the excited ${ }^{5} \mathrm{D}_{0}$ levels to the ${ }^{7} \mathrm{~F}_{\mathrm{J}}$ levels $(\mathrm{J}=0-3)$ of $\mathrm{Eu}^{3+}$ ion. The variation of the emission intensities as well as ${ }^{5} \mathrm{D}_{0}$ lifetime in function of $\mathrm{Eu}^{3+}$ content and $\mathrm{pH}$ value are closely connected to morphology and crystallinity of $\mathrm{GdBO}_{3}$ host nanomaterial. Besides, it has been found that the $\mathrm{Eu}^{3+}$ and $\mathrm{pH}$ values have an important influence on the asymmetry ratio parameter $\mathrm{R}$ between the red ${ }^{5} \mathrm{D}_{0} \rightarrow{ }^{7} \mathrm{~F}_{2}$ and orange ${ }^{5} \mathrm{D}_{0} \rightarrow{ }^{7} \mathrm{~F}_{1}$ transitions intensities. The chromaticity coordinates are located in the orange-red region with high luminescence efficiency and therefore, $\mathrm{GdBO}_{3}: \mathrm{Eu}^{3+}$ nanophosphors make them potentially useful for optical devices.

\section{CRediT authorship contribution statement}

M. Seraiche: Investigation, Formal analysis, Data curation, Visualization, Writing - original draft, Writing review \& editing. L. Guerbous: Validation, Visualization, Project administration, Writing - original draft, Writing - review \& editing. R. Mahiou: Methodology, Formal analysis, Writing - review \& editing. A. Potdevin: Methodology, Formal analysis, Writing - review \& editing.

\section{Declaration of competing interest}

The authors declare that they have no known competing financial interests or personal relationships that could have appeared to influence the work reported in this paper.

\section{References}

The corrections made in this section will be reviewed and approved by a journal production editor. The newly added/removed references and its citations will be reordered and rearranged by the production team.

[1] Mansuy C., Nedelec J.M., Dujardin C., Mahiou R., Opt. Mater. 29 (2007) 697-702, doi:10.1016/j.optmat.2005.10.017.

[2] Lou L., Boyer D., Bertrand-Chadeyron G., Bernstein E., Mahiou R., Mugnier J., Opt. Mater. 15 (2000) 1-6, doi:10.1016/S0925-3467(00)00014-8.

[3] Chen H., Wang G.D., Chuang Y.J., Zhen Z., Chen X., Biddinger P., Hao Z., Liu F., Shen B., Pan Z., Xie J., Nano Lett. 15 (2015) 2249-2256, doi:10.1021/n1504044p. 
Wang Y., Uheda K., Takizawa H., Mizumoto U., Endo T., J. Electrochem. Soc. 148 (2001) G430, doi:10.1149/1.1383778.

[5] Keszler D.A., Curr. Opin. Solid State Mater. Sci. 1 (1996) 204-211, doi:10.1016/S13590286(96)80085-4.

[6] Koike J., Kojima T., Toyonaga R., Kagami A., Hase T., Inaho S., J. Electrochem. Soc. 126 (1979) 1008, doi:10.1149/1.2129164.

[7] Ronda C.R., Jüstel T., Nikol H., J. Alloys Compd. 275-277 (1998) 669-676, doi:10.1016/S09258388(98)00416-2.

[8] Kim C.H., Kwon I.E., Park C.H., Hwang Y.J., Bae H.S., Yu B.Y., Pyun C.H., Hong G.Y., J. Alloys Compd. 311 (2000) 33-39, doi:10.1016/S0925-8388(00)00856-2.

[9] Sambandan E., Inorganic Materials Chemistry: General Concept and Research Topics, iUniverse, 9780595531738, 2008.

[10] Ren M., Lin J.H., Dong Y., Yang L.Q., Su M.Z., You L.P., Chem. Mater. 11 (1999), doi:10.1021/cm990022o.

[11] Grzyb T., Kubasiewicz K., Szczeszak A., Lis S., Dalton Trans. 44 (2015) 4063-4069, doi:10.1039/C4DT03667K.

[12] Chadeyron G., Mahiou R., EL-Ghozzi M., Arbus A., Zambon D., Cousseins J.C., J. Lumin. $72-$ 74 (1997) 564-566, doi:10.1016/S0022-2313(96)00191-3.

[13] Mansuy C., Nedelec J.-M., Mahiou R., J. Matter. Chem 14 (2004) 3274-3280, doi:10.1039/B405402D.

[14] Kim K., Moon Y.-M., Choi S., Jung H.-K., Nahm S., Mater. Lett. 62 (2008) 3925, doi:10.1016/j.matlet.2008.04.085.

[15] Dutta D.P., Tyagi A.K., Solid State Phenom. $155 \quad$ (2009) 113-143, doi:10.4028/www.scientific.net/SSP.155.113.

[16] Yang L., Zhou L., Huang Ying, Tang Z., Mater. Chem. Phys. 131 (2011) 477-484, doi:10.1016/j.matchemphys.2011.10.007.

[17] Guerbous L., Seraiche M., Krachni O., J. Lumin. $134 \quad$ (2013) 165-173, doi:10.1016/j.jlumin.2012.08.053.

[18] Shen H., Feng S., Wang Y., Gu Y., Zhou J., Yang H., Feng G., Li L., Wang W., Liu X., Xu D., J. Alloys Compd. 550 (2013) 531-535, doi:10.1016/j.jallcom.2012.10.156.

[19] Boyer D., Leroux F., Bertrand G., Mahiou R., J. Non-Cryst. Solides 306 (2002) 110-119, doi:10.1016/S0022-3093(02)01152-3.

[20] Newnham R.E., Redman M.J., Santoro R.P., J. Am. Ceram. Soc. 46 (1963) 253-256, doi:10.1111/j.1151-2916.1963.tb11721.x. 
[21] Bradley W.F., Graf D.L., Roth R.S., Acta Crystallogr. 20 (1966) 283-287, doi:10.1107/S0365110X66000549.

[22] Lin J., Sheptyakov D., Wang Z., Allenspach P., Chem. Mater. 16 (2004) 2418-2424, doi:10.1021/cm0499388.

[23] Morgan P.E.D., Carroll P.J., Lange F.F., Mater. Res. Bull. 12 (1977) 251-259, doi:10.1016/00255408(77)90142-8.

[24] Boyer D., Bertrand G., Mahiou R., J. Lumin. 104 (2003) 229-237, doi:10.1016/S00222313(03)00077-2.

[25] Szczeszak A., Grzyb T., Barszcz B., Nagirnyi V., Kotlov A., Lis S., Inorg. Chem. 52 (2013) 4934-4940, doi:10.1021/ic302525k.

[26] Rambabu U., Han S.D., RSC Adv. 3 (2013) 1368-1379, doi:10.1039/C2RA21304D.

[27] Jiang X., Yan C., Sun L., Wei Z., Liao C., J. Solid State Chem. 175 (2003) 245-251, doi:10.1016/S0022-4596(03)00276-7.

[28] Tao Y., Zhao G.W., Zhang W.P., Xia S.D., Mater. Res. Bull. 32 (1997) 501-506, doi:10.1016/S0025-5408(97)00007-X.

[29] Jiang X., Sun L., Yan C., J. Phys. Chem. B 108 (2004) 3387-3390, doi:10.1021/jp037301q.

[30] Nedelec J.M., Mansuy C., Mahiou R., J. Mol. Struct. 651-653 (2003) 165-170, doi:10.1016/S0022-2860(03)00104-2.

[31] Zhang L.Y., Fu W.W., Zheng G.H., Dai Z.X., Zhu Y.N., Mu J.J., J. Mater. Sci. Mater. Electron. 27 (2016) 5164-5174, doi:10.1007/s10854-016-4409-5.

[32] Shi X., Liu Y., Zhang J., Zhang K., Li P., Zuo H., Li J., Ceram. Int. 41 (2015) 3162-3168, doi:10.1016/j.ceramint.2014.10.164.

[33] Guerbous L., Derbal M., Chaminade J.P., J. Lumin. 130 (2010) 2469-2475, doi:10.1016/j.jlumin.2010.08.014.

[34] Szczeszak A., Kubasiewicz K., Lis S., Opt. Mater. 35 (2013) 1297-1303, doi:10.1016/j.optmat.2013.02.001.

[35] Williamson G.K., Hall W.H., Acta Metall. 1 (1953) 22-31, doi:10.1016/0001-6160(53)90006-6.

[36] Seraiche M., Guerbous L., Kechouane M., Potdevin A., Chadeyron G., Mahiou R., J. Lumin. 192 (2017) 404-409, doi:10.1016/j.jlumin.2017.07.012.

[37] Sharma P.K., Jilavi M.H., Varadan V.K., Schmidt H., Journal of Physics and Chemistry of Solides 63 (2002) 171-177, doi:10.1016/S0022-3697(01)00124-X.

[38] Shmuraka S.Z., Kedrova V.V., Kiseleva A.P., Fursovaa T.N., Rybchenkoa O.G., Phys. Solid State 60 (2018) 2579-2592, doi:10.1134/S1063783419010244. 
Szczeszak A., Grzyb T., Lis S., Wigl R.J., Dalton Trans. 41 (2012) 5824-5831, doi:10.1039/C2DT12154A.

[40] Boyer D., Bertrand-Chadeyron G., Mahiou R., Caperaa C., Cousseins J.C., J. Mater. Chem. 9 (1999) 211-214, doi:10.1039/A804514C.

[41] Wei Z., Sun L., Liao C., Yan C., Huang S., Appl. Phys. Lett. 80 (2002) 1447, doi:10.1063/1.1452787.

[42] Shen H., Feng S., Wang Y., Gu Y., Zhou J., Yang H., Feng G., Li e L., Wang W., Liu X., Xu D., J. Alloys Compd. 550 (2013) 531-535, doi:10.1016/j.jallcom.2012.10.156.

[43] Reddy A.A., Das S., Ahmad S., Babu S.S., Ferreira J.M.F., Prakash G.V., RSC Adv. 2 (2012) 8768-8776, doi:10.1039/C2RA20866K.

[44] Zhu Y., Liang Y., Liu S., Li Kai, Wu X., Xu R., J. Alloys Compd. 685 (2016) 848-859, doi:10.1016/j.jallcom.2016.06.215.

[45] Blasse G., J. Chem. Phys. 45 (1966) 2356, doi:10.1063/1.1727946.

[46] Wiglusz R.J., Grzyb T., Lis S., Strek W., J. Nanosci. Nanotechnol. 9 (2009) 5803-5810, doi:10.1166/jnn.2009.1259.

\section{Highlights}

- $\mathrm{GdBO}_{3}: \mathrm{Eu}^{3+}$ nanophosphors were prepared using acetylacetone assisted aqueous sol-gel method; with two essential parameters: $\mathrm{Eu}^{3+}$ concentration and $\mathrm{pH}$ value.

- Effects of $\mathrm{Eu}^{3+}$ content and the $\mathrm{pH}$ value on the morphology, structural and luminescence spectroscoy properties have been investigated and highlighted.

- $\mathrm{GdBO}_{3}: \mathrm{qEu}^{3+}$ hexagonal pure phase shows a correlation on the europium content and $\mathrm{pH}$ value.

- High orange-red color emission from ${ }^{5} \mathrm{D}_{0}$ levels to the ${ }^{7} \mathrm{~F}_{\mathrm{J}}$ levels $(\mathrm{J}=0-3)$ of $\mathrm{Eu}^{3+}$ ion was observed.

- It was found that $10 \%$ concentration of $\mathrm{Eu}^{3+}$ presents the quenching of emission and sample $\mathrm{pH}=10$ exhibit the highest emission intensity in $\mathrm{GdBO}_{3}$.

\section{Queries and Answers}

Query: Your article is registered as a regular item and is being processed for inclusion in a regular issue of the journal. If this is NOT correct and your article belongs to a Special Issue/Collection please contact s.nataraj@elsevier.com immediately prior to returning your corrections.

Answer: Yes 
Query: Please confirm that given names and surnames have been identified correctly and are presented in the desired order and please carefully verify the spelling of all authors' names.

Answer: M. Seraiche ${ }^{\mathbf{a} *}$, L. Guerbous ${ }^{\mathbf{b} * *}$, R. Mahiou ${ }^{\mathbf{c}}$, A Potdevin ${ }^{\mathbf{c} \text { a }}$ Faculty of Sciences, M ${ }^{\text {ed }}$ Boudiaf aUniversity -M'sila- BP 166 M'sila 28000, Algeria

b Laser Physics Department, Physics Division, Algiers Nuclear Research Center(CRNA), 02, bd Frantz Fanon, BP 399, Algiers 16000, Algeria

c Université Clermont Auvergne, CNRS, SIGMA Clermont, Institut de Chimie de Clermont-Ferrand, F-63000, Clermont-Ferrand, France Corresponding authors: *M. Seraiche: seraiche28@hotmail.fr, **L. Guerbous guerbous@yahoo.fr

Query: Please confirm that the provided emails “seraiche28@hotmail.fr, guerbous@yahoo.fr” are the correct address for official communication, else provide an alternate e-mail address to replace the existing one, because private e-mail addresses should not be used in articles as the address for communication.

Answer: Yes, It is correct

Query: Correctly acknowledging the primary funders and grant IDs of your research is important to ensure compliance with funder policies. We could not find any acknowledgement of funding sources in your text. Is this correct?

Answer: Yes

Query: Highlights should only consist of "125" characters per bullet point, including spaces. The highlights provided are too long; please edit them to meet the requirement.

Answer: $\mathrm{GdBO}_{3}: \mathrm{Eu}^{3+}$ nanophosphors were prepared using acetylacetone assisted aqueous sol-gel route with Eu ${ }^{3+}$ content and $\mathrm{pH}$ value; $\cdot$ Effects of $\mathrm{Eu}^{3+}$ content and the $\mathrm{pH}$ value on the morphology, structural and luminescence properties were investigated. $\mathrm{GdBO}_{3}: \mathrm{Eu}^{3+}$ hexagonal pure phase shows a correlation on the europium content and $\mathrm{pH}$ value. High orange-red color emission from ${ }^{5} \mathrm{D}_{0}$ levels to the ${ }^{7} \mathrm{~F}_{\mathrm{J}}$ levels $(\mathrm{J}=0-3)$ of $\mathrm{Eu}^{3+}$ ion was observed. For $10 \% \mathrm{Eu}^{3+}$ content the quenching was found for $\mathrm{pH}=10$ exhibiting the highest emission intensity. 